\title{
Learning curves for transapical transcatheter aortic valve replacement in the PARTNER-I trial: Technical performance, success, and safety
}

\author{
Rakesh M. Suri, MD, DPhil, ${ }^{\mathrm{a}}$ Sa'ar Minha, MD, ${ }^{\mathrm{b}}$ Oluseun Alli, MD, ${ }^{\mathrm{c}}$ Ron Waksman, MD, ${ }^{\mathrm{d}}$ \\ Charanjit S. Rihal, MD, ${ }^{\mathrm{e}}$ Lowell P. Satler, MD, ${ }^{\mathrm{d}}$ Kevin L. Greason, MD,${ }^{\mathrm{e}}$ Rebecca Torguson, MPH, ${ }^{\mathrm{d}}$ \\ Augusto D. Pichard, MD, ${ }^{\mathrm{d}}$ Michael Mack, MD, ${ }^{\mathrm{f}}$ Lars G. Svensson, MD, PhD, \\ Jeevanantham Rajeswaran, $\mathrm{PhD},{ }^{\mathrm{a}}$ Ashley M. Lowry, MS, ${ }^{\mathrm{a}}$ John Ehrlinger, $\mathrm{PhD},{ }^{a}$ \\ Stephanie L. Mick, MD, ${ }^{\mathrm{a}}$ E. Murat Tuzcu, MD, ${ }^{\mathrm{a}}$ Vinod H. Thourani, MD, ${ }^{\mathrm{g}}$ Raj Makkar, MD, \\ David Holmes, MD, ${ }^{\mathrm{e}}$ Martin B. Leon, MD, ${ }^{\mathrm{i}}$ and Eugene H. Blackstone, MD ${ }^{\mathrm{a}}$
}

\begin{abstract}
Objectives: Introduction of hybrid techniques, such as transapical transcatheter aortic valve replacement (TA-TAVR), requires skills that a heart team must master to achieve technical efficiency: the technical performance learning curve. To date, the learning curve for TA-TAVR remains unknown. We therefore evaluated the rate at which technical performance improved, assessed change in occurrence of adverse events in relation to technical performance, and determined whether adverse events after TA-TAVR were linked to acquiring technical performance efficiency (the learning curve).
\end{abstract}

Methods: From April 2007 to February 2012, 1100 patients, average age $85.0 \pm 6.4$ years, underwent TA-TAVR in the PARTNER-I trial. Learning curves were defined by institution-specific patient sequence number using nonlinear mixed modeling.

Results: Mean procedure time decreased from 131 to 116 minutes within 30 cases $(P=.06)$ and device success increased to $90 \%$ by case $45(P=.0007)$. Within 30 days, 354 patients experienced a major adverse event (stroke in 29, death in $96)$, with possibly decreased complications over time $(P \sim .08)$. Although longer procedure time was associated with more adverse events $(P<.0001)$, these events were associated with change in patient risk profile, not the technical performance learning curve $(P=.8)$.

Conclusions: The learning curve for TA-TAVR was 30 to 45 procedures performed, and technical efficiency was achieved without compromising patient safety. Although fewer patients are now undergoing TAVR via nontransfemoral access, understanding TA-TAVR learning curves and their relationship with outcomes is important as the field moves toward next-generation devices, such as those to replace the mitral valve, delivered via the left ventricular apex. (J Thorac Cardiovasc Surg 2016;152:773-80)

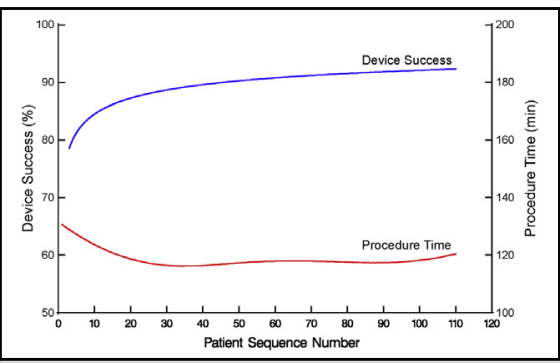

Device success increased and procedure time decreased within 30 to 45 cases.

\section{Central Message}

The learning curve for TA-TAVR did not compromise patient safety.

\section{Perspective}

The learning curve for TA-TAVR was 30 to 45 cases and technical competence was achieved without compromising patient safety. Although fewer patients are undergoing TAVR via nonTF access, understanding TA-TAVR learning curves and their relationship with outcomes is important as the field moves toward nextgeneration devices delivered via the left ventricular apex.

See Editorial Commentary page 781
From the ${ }^{\mathrm{a} C l e v e l a n d}$ Clinic, Cleveland, Ohio; ${ }^{\mathrm{b}}$ Assaf-Harofeh Medical Center, Zerifin, Israel; ${ }^{\mathrm{c}}$ University of Alabama, Birmingham, Ala; ${ }^{\mathrm{d}}$ MedStar Washington Hospital Center, Washington, DC; ${ }^{\mathrm{e}}$ Mayo Clinic, Rochester, Minn; ${ }^{\mathrm{f}}$ Baylor Scott \& White Health, Plano, Tex; ${ }^{\mathrm{g}}$ Emory University School of Medicine, Atlanta, Ga; ${ }^{\mathrm{h}}$ Cedars Sinai Medical Center, Los Angeles, Calif; and ${ }^{\mathrm{i}}$ Columbia University Medical Center/New York-Presbyterian Hospital, New York, NY.

The nonlinear mixed-effects models were developed with support from National Institutes of Health grant 1R01HL103552-01A1, Ancillary Comparative Effectiveness of Atrial Fibrillation Ablation Surgery.

Data used for this study were from a December 20, 2012, locked data extract provided to the PARTNER Publications Office by Edwards Lifesciences. These data have been approved for use in research by institutional review boards at each institution. All patients provided written informed consent. Data analysis was performed by investigators at Cleveland Clinic, with no sponsor involvement in study proposal or design, analyses, interpretation, or the decision to publish.

Clinical Trial Registration: http://clinicaltrials.gov/ct2/show/NCT00530894; NCT00530894.

Received for publication Oct 6, 2015; revisions received March 30, 2016; accepted for publication April 7, 2016; available ahead of print May 20, 2016.

Address for reprints: Rakesh M. Suri, MD, DPhil, Department of Thoracic and Cardiovascular Surgery, Cleveland Clinic, 9500 Euclid Ave., J4-1, Cleveland, OH 44195 (E-mail: surir@ccf.org).

$0022-5223 / \$ 36.00$

Copyright (C) 2016 by The American Association for Thoracic Surgery

http://dx.doi.org/10.1016/j.jtcvs.2016.04.028 


\section{Abbreviations and Acronyms \\ $\mathrm{AR}=$ aortic regurgitation \\ PARTNER $=$ Placement of Aortic Transcatheter Valves \\ $\mathrm{TA}=$ transapical \\ TAVR $=$ transcatheter aortic valve replacement \\ $\mathrm{TF} \quad=$ transfemoral}

\section{Scanning this QR code will take you to the appendices, supple- mental figures, tables, and video for this article.}

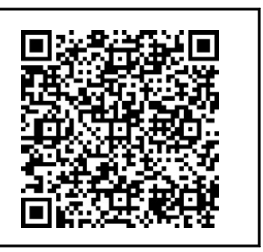

Transcatheter aortic valve replacement (TAVR) has revolutionized treatment of patients with severe senile calcific aortic valve stenosis. As with introduction of any complex procedure, particularly one requiring a team approach, a set of skills must be mastered to achieve technical competence: the learning curve. ${ }^{1,2}$ To date, the time necessary to traverse this learning phase for transapical (TA) TAVR remains unknown, and it is uncertain whether this learning curve compromises successful valve replacement and patient safety.

International TAVR trials have been designed to mandate a "transfemoral (TF) first" access strategy, with alternative access, such as the TA approach, reserved for patients with severe peripheral vasculopathy. ${ }^{3,4}$ Because clinical risk factors associated with peripheral vascular disease may preclude $\mathrm{TF}$ access, understanding learning curves associated with TA-TAVR is necessary to ensure this procedure is performed successfully and safely. In this study, we sought to answer the following questions: (1) Was there a technical performance learning curve for TA-TAVR in the Placement of Aortic Transcatheter Valves (PARTNER) I trial? (2) Were there associated consequences during this period, such as occurrence of adverse events early after TA-TAVR? (3) Did the technical performance learning curve compromise successful valve replacement and patient safety?

\section{METHODS \\ Patients}

From April 2007 to February 2012, 1100 patients from 24 PARTNER-I trial institutions underwent TA-TAVR. Average age was $85.0 \pm 6.4$ years and mean transaortic gradient was $44 \mathrm{~mm} \mathrm{Hg}$, with a mean aortic valve area of $0.64 \mathrm{~cm}^{2}$, consistent with severe senile calcific aortic stenosis. Nearly all patients had peripheral vascular disease $(98 \%)$, hypertension (96\%), and hyperlipidemia ( $87 \%$ ), and $51 \%$ had undergone previous coronary artery bypass grafting and $46 \%$ previous percutaneous coronary intervention; $43 \%$ had cerebral vascular disease, $45 \%$ chronic pulmonary disease, and 36\% diabetes (Table E1). Median number of cases performed per institution was 48, with 2 the lowest and 112 the highest (Figure E1). Because prevalence of TA-TAVR steadily increased during the PARTNER-I trial (Figure E2) and the interval between TA-TAVR cases decreased at nearly all institutions, that is, institution volume increased (Figure E3), we included all as-treated TA-TAVR patients who were part of both randomized and nonrandomized cohorts (Table E2).

\section{Study Device and Procedure}

The Edwards SAPIEN transcatheter heart valve system (Edwards Lifesciences, Irvine, Calif) used in the PARTNER-I trial consisted of a trileaflet bovine pericardial valve (model 9000TFX) and a balloon-expandable, stainless steel support frame. Technical details of TA-TAVR have been previously described. ${ }^{5}$ The procedures themselves were performed by the institution's own team. An experienced industry technical representative was also in attendance for each case, along with qualified interventional cardiologists. Cardiac surgery proctors observed, on average, the first 3 procedures.

\section{Study Design}

This is an as-treated analysis. Before start of the PARTNER-I trial, 40 patients underwent TA-TAVR with the SAPIEN device at 3 institutions: Columbia University $(\mathrm{n}=13)$, Cleveland Clinic $(\mathrm{n}=12)$, and Baylor Health Care System $(n=15)$. For purposes of learning curve analyses, sequential numbering of patients for these 3 institutions was adjusted to reflect the number of procedures that had been performed before the PARTNER-I trial; however, patient-level data were unavailable for these 40 patients. To illustrate, 12 patients underwent TA-TAVR at Cleveland Clinic before the trial, so patient sequence number for analysis started at 13 .

\section{Data}

Data used for this study were from a December 20, 2012, locked data extract provided to the PARTNER Publications Office by Edwards Lifesciences. These data have been approved for use in research by institutional review boards at each institution. All patients provided written informed consent.

\section{Endpoints}

Technical performance. Among the many technical performance measures for which learning curves were assessed, we selected those that would illustrate technical efficiency and the influence on the learning curve of accumulating external experience: procedure time, fluoroscopy time, contrast volume used, and number of postdeployment dilatations. Procedure time was the time from surgical incision until incision closure. Influence of external experience on technical performance was assessed by the institution's date of entry into the trial.

Outcomes. Intra- and postprocedure events assessed included device success, adverse events occurring during the procedure, length of postprocedure hospital stay, and major adverse events occurring within 30 days. All were adjudicated by a clinical events committee and defined as follows:

1. Device success: Delivery and deployment of the prosthesis and retrieval of the delivery catheter, resulting in an aortic valve area larger than $0.9 \mathrm{~cm}^{2}$, with less than $3+$ aortic regurgitation (AR) in the earliest evaluable echocardiogram and only a single valve deployed and implanted in the correct anatomical position. Even if another valve was required that successfully treated, for example, severe paravalvular leak, this was classified as device failure. This definition closely parallels that of the Valve Academic Research Consortium. ${ }^{6}$

2. Adverse events during procedure: Intraprocedural events included vascular hemorrhage, bleeding, arrhythmia, hypotension, conduction defects, abnormal laboratory values, and paravalvular leak (Table E3). Definitions of these adverse events followed PARTNER-I trial protocol definitions. ${ }^{7}$ 
3. Length of postprocedure hospital stay: Interval in days between index procedure date and hospital discharge date after the procedure.

4. Major adverse events occurring within 30 days: A composite endpoint that included adverse events during the procedure, all-cause mortality, stroke, major bleeding, and major vascular complications (Appendix E1).

\section{Data Analysis}

Analyses were performed using SAS statistical software (SAS v9.2; SAS, Inc, Cary, NC) and R software version 3.0.2 (http://www. R-project.org).

Learning curves were explored using 3 general strategies, and a fourth special strategy for procedure time (Appendix E2). First, a learning curve profile for all technical and outcomes endpoints was constructed for each institution according to institution-specific patient sequence number. These were summarized for continuous data using locally weighted scatterplot smoothing (loess). ${ }^{8}$ Second, an overall learning curve profile across all institutions was constructed using mixed-effects modeling to account for correlation of patients within an institution. This methodology permitted us to derive a confidence band around the point estimates and to generate numerical estimates at selected sequence numbers. To obtain tests of statistical significance, this analysis was supplemented by focused modeling of each learning curve variable with patient sequence number. Third, because institutions entered the trial at different times, which confounds date-ofprocedure effects, we investigated the effect of entry date of each institution into the PARTNER-I trial on learning curves using a combination of data exploration and estimation of trends according to broad categories of trial entry date.

For procedure time, a more intense modeling approach was used to estimate the number of cases required to reach a steady value. For this, we applied a commonly used hyperbolic model for learning curves that assumes that procedure time would decrease with experience at an institution-specific rate, but eventually would reach an institutionspecific average minimum time (mathematically, an asymptote; see Appendix E2). A nonlinear mixed-effects method was used for this. By definition, an asymptote is reached only with an infinite number of cases, so we chose 15 seconds as the difference between successive procedure times to indicate that the curve had become essentially flat. This model permitted us to perform a multivariable analysis that included institution-specific patient sequence number, interval between procedures (an instantaneous measure of the institution's case volume), and trial entry date.

Association of outcomes learning curves with patient variables and technical performance metrics. We investigated the association of major adverse events occurring within 30 days of TA-TAVR and post-TAVR length of stay with patient variables (Appendix E3) and technical performance metrics (procedure time, fluoroscopy time, contrast volume, pacing count during balloon aortic valvotomy and prosthesis deployment, and number of postdeployment dilatations). Although procedure time demonstrated a clear learning curve, patient factors and events occurring during the procedure may prolong it. Therefore, to explore the possible link between this learning curve and 30-day major adverse events, we decomposed procedure time into 3 components:

1. Procedure time learning curve: For each patient, we predicted procedure time by a hyperbolic mixed-effects model of patient sequence number as described in Appendix E2. This analysis accounted for institution trial entry date, interval between cases, and patient sequence number.

2. Patient factors influencing procedure time: For each patient, we predicted procedure time by a linear mixed-effects parsimonious model of patient factors. This analysis accounted for institutional variability as a random effect.
3. Unmeasured factors prolonging procedure time: The difference between observed procedure time and that accounted for by the technical learning curve and patient factors was assumed to represent patient selection factors, events during the procedure prolonging its duration, and other unmeasured variables.

Three variables representing each of these 3 components were then forced into models of 30-day major adverse events, along with patient variables.

Missing values. We used fivefold multiple imputation for missing values of variables used in multivariable analyses, as described in Appendix E2.'

Presentation. Continuous variables are summarized as mean \pm standard deviation or as equivalent 15 th, 50 th (median), and 85 th percentiles when distribution of values is skewed. Categorical variables are summarized by frequencies and percentages. Confidence limits or bands are $68 \%$, which is consistent with 1 standard error of the point estimate, but may be asymmetric.

\section{RESULTS}

\section{Technical Performance}

Mean procedure time was $120 \pm 67$ minutes (Table 1), decreasing from 131 to 116 minutes by case 30 (Table E4), and remaining constant at approximately 117 minutes thereafter (Figures 1 and 2, A, Table E4; $P=.06)$. On average, it took $1.7 \pm 0.46$ years for institutions to perform 30 cases. Institutional values of non-riskadjusted average minimum (asymptotic) procedure time ranged from 77 to 222 minutes (Figure E4, A). This minimum was reached after 5 to 52 cases, but typically 15 (Figure E4, B). Among the last 5 institutions entering the trial, 9 cases were needed to reach a minimum procedure time (Figure E4, C), although these institutions tended to have a longer asymptotic procedure time than those entering the trial near its beginning (Figure E4, D). The average calendar time it took institutions to reach their asymptote was $14.0 \pm 6.9$ months. We were unable to demonstrate that higher institutional volume, assessed as lower interval between sequential cases, was associated with procedure time after accounting for sequence number and trial entry date $(P=.5)$.

Fluoroscopy time averaged $14 \pm 10$ minutes (Figure 2, $B$, Table 1) and decreased only slightly from 14 to 12 minutes by case 60 (Table E4; $P=.01$ ). Median contrast volume was $90 \mathrm{~mL}$ (15th and 85th percentiles 45 and $150 \mathrm{~mL}$ ), decreasing from 114 to $90 \mathrm{~mL}$ by case 60 (Figure 2, $C$, Table E4; $P<.0001)$. Frequency of postdeployment dilatations remained low (none in $89 \%$ of patients) and constant across the experience (Figure 2, $D$, Table E4; $P=.5$ ).

\section{Outcomes}

Device success increased from $72 \%$ to $80 \%$ by 4 cases and to $90 \%$ within 45 cases (Figures 1 and 3, Table E4; $P=.0007)$. On average, it took $2.20 \pm 0.48$ years for institutions to perform 45 cases. Intraprocedural adverse events fell from $31 \%$ to $25 \%$ by 15 cases, but with wide confidence limits, and remained constant thereafter 
TABLE 1. Technical performance and outcomes endpoints after transapical transcatheter aortic valve replacement

\begin{tabular}{|c|c|c|}
\hline Endpoint & $\mathbf{n}^{*}$ & n $(\%)$ \\
\hline \multicolumn{3}{|l|}{ Technical performance } \\
\hline Procedure time, min & 1092 & $120.0 \pm 66.7$ \\
\hline Fluoroscopy time, min & 1048 & $13.5 \pm 10.5$ \\
\hline Contrast medium, mL & 1057 & $45 / 90 / 150 \ddagger$ \\
\hline Postdilatations & 1096 & \\
\hline 0 & & $980(89)$ \\
\hline 1 & & $103(9.4)$ \\
\hline 2 & & $12(1.1)$ \\
\hline 3 & & $1(0.09)$ \\
\hline \multicolumn{3}{|l|}{ Outcomes } \\
\hline Device success & 1061 & $930(88)$ \\
\hline \multicolumn{3}{|l|}{ Aortic regurgitation grade at discharge } \\
\hline Total & 1021 & \\
\hline None/trace & & $587(57)$ \\
\hline Mild & & $366(36)$ \\
\hline Moderate & & $64(6.3)$ \\
\hline Severe & & $4(0.39)$ \\
\hline Transvalvular & 1020 & \\
\hline None/trace & & 907 (89) \\
\hline Mild & & $109(11)$ \\
\hline Moderate & & $4(0.39)$ \\
\hline Severe & & $0(0)$ \\
\hline Paravalvular & 1018 & \\
\hline None/trace & & $657(65)$ \\
\hline Mild & & $305(30)$ \\
\hline Moderate & & $53(5.2)$ \\
\hline Severe & & $3(0.29)$ \\
\hline Adverse events during procedure & 1100 & $257(23)$ \\
\hline Myocardial perforation & 1100 & $11(1.0)$ \\
\hline Ventricular injury & 1100 & $4(0.36)$ \\
\hline Adverse events within $30 \mathrm{~d}$ & 1100 & \\
\hline Stroke & & $29(2.6)$ \\
\hline Mortality & & $96(8.7)$ \\
\hline Major bleeding & & $97(8.8)$ \\
\hline Major vascular complication & & $39(3.5)$ \\
\hline Composite 30-d major adverse event & 1100 & $354(32)$ \\
\hline Postprocedure length of stay, d & 1081 & $5 / 8 / 15 \ddagger$ \\
\hline
\end{tabular}

*Patients with data available. $\dagger$ Mean \pm standard deviation. $\ddagger 15$ th/50th/85th percentiles.

(Figure 4, $A$, Table E4; $P=.3$ ). Specifically, 15 patients experienced intraprocedural myocardial perforation or ventricular injury (Table 1), with no significant trend over patient sequence number (Figure E5, $A, P=.4$ ) or years from institution trial entry date (Figure E5, $B, P=.8$ ). Median postprocedure length of hospital stay was 8 days (15th and 85th percentiles 5 and 15 days) and became slightly shorter with increasing experience (Figure 5, Table E4; $P=.13$ ); after risk adjustment, postprocedure hospital stay was found to be statistically significantly shorter with increasing sequence number $(P=.04)$.

A total of $46 \%$ of patients had none/trace paravalvular AR initially, improving to $66 \%$ within the first 30 cases, whereas moderate paravalvular AR fell from $11 \%$ to

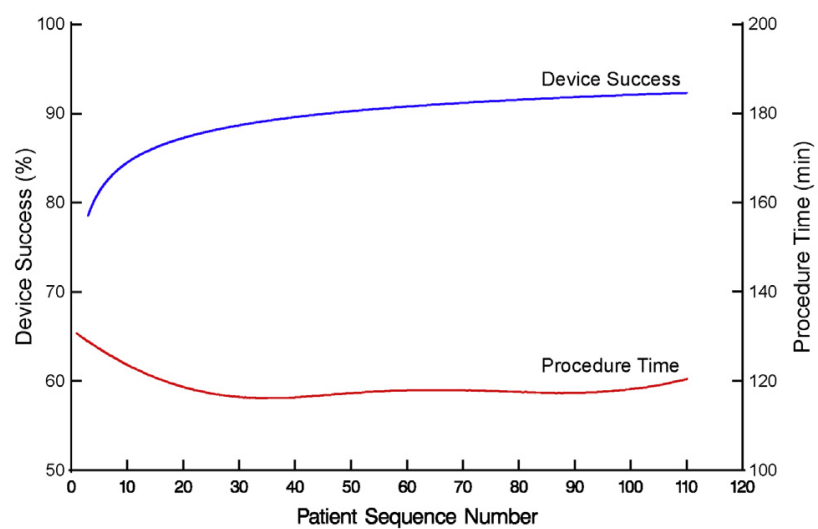

FIGURE 1. Overall profile of procedure time and device success for transapical transcatheter aortic valve replacement, ordered by institution-specific patient sequence number. Solid red line represents average procedure time adjusted for institution and solid blue line represents average percent of patients who experienced successful device deployment.

5.1\% (Figure 6, Table E4; $P=.10$ ). Transvalvular AR was minimal across experience, with $84 \%$ of patients having none/trace transvalvular AR and $15 \%$ mild initially; prevalence of none/trace transvalvular AR increased to $89 \%$ and mild decreased to $10 \%$ within 30 cases (Figure E6, $A$, Table E4; $P=.2$ ). Initially, $41 \%$ of patients had none/trace total AR, which improved to $58 \%$ by case 30 , whereas moderate total AR fell from $12 \%$ to $6.3 \%$ (Figure E6, $B$, Table E4; $P=.13$ ).

Within 30 days, 354 patients (32\%) experienced at least 1 major adverse event: $29(2.6 \%)$ had a stroke, $97(8.8 \%)$ a major bleeding episode, and $39(3.5 \%)$ a major vascular complication; 96 patients $(8.7 \%)$ died (Table 1, Figure E7). Occurrence of a composite event (adverse event or death) within 30 days fell from $51 \%$ initially to $29 \%$ by case 30 , then rose slightly to $36 \%$ by case 90 (Figure $4, B$, Table E4; $P=.01$ ).

\section{Influence of Technical Performance on Outcomes}

Total procedure time was strongly associated with outcomes, with a nearly linear increase in risk of 30-day major adverse events (Figure 7). The most significant risk factors for 30-day major adverse events were longer procedure time, baseline antiplatelet drug therapy, higher international normalized ratio, and lower hemoglobin, but only possibly patient sequence number (Table E5; $P=.09$ ). On further analysis (Table E6), when procedure time was deconstructed into technical performance, patient characteristics, and unknown factors, there was no evidence $(P=.8)$ of an effect of technical performance, as reflected by procedure time, on the composite endpoint; rather, patient profile $(P=.05)$ and unknown variables $(P<.0001)$ were associated, although a possible effect of sequence number persisted $(P=.06)$. 

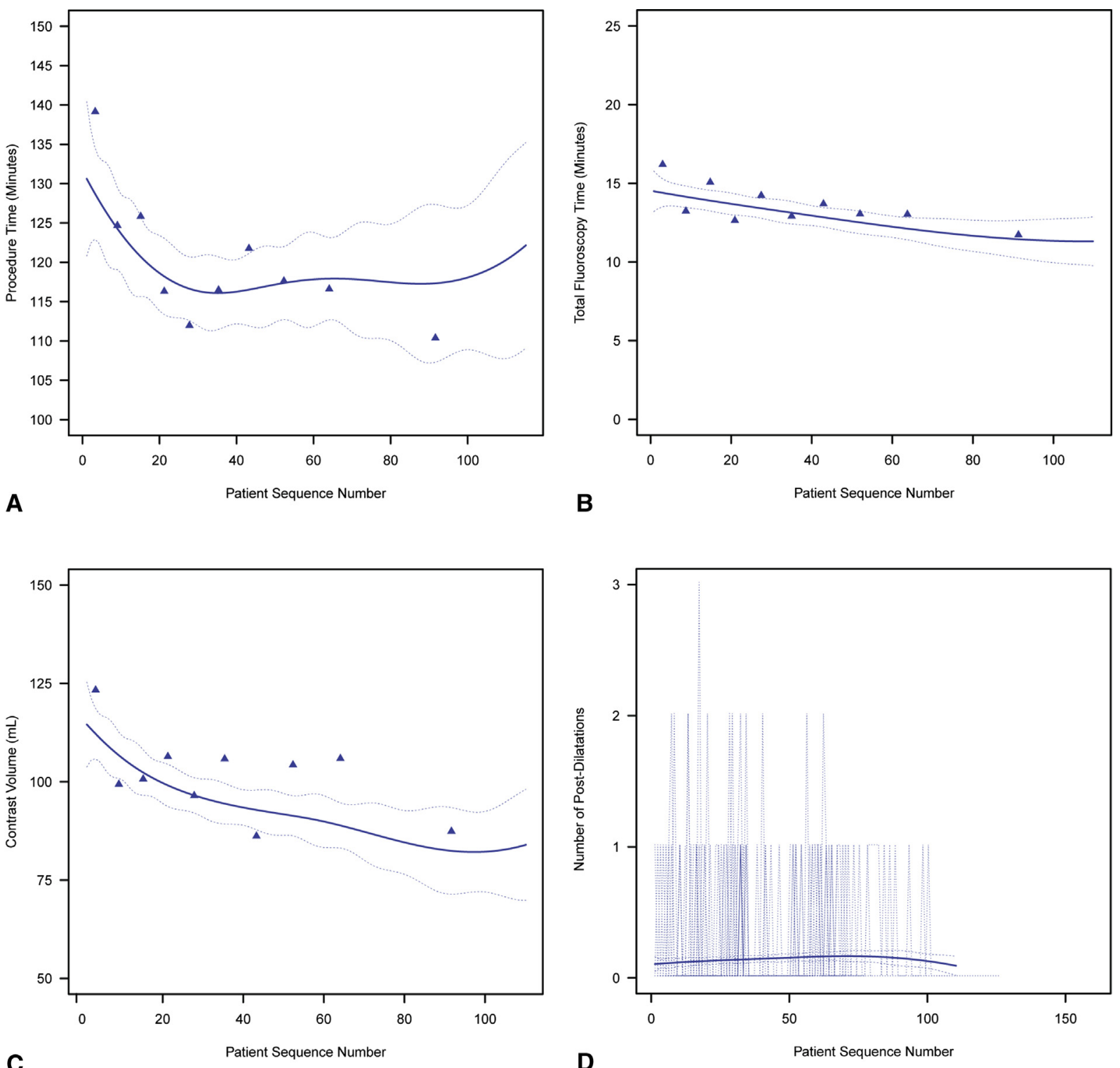

FIGURE 2. Overall profile of mean technical performance for transapical transcatheter aortic valve replacement, ordered by institution-specific patient sequence number. Solid line represents average profiles adjusted for institution, enclosed within a dashed $68 \%$ confidence band equivalent to 1 standard error. For crude verification of model fit, symbols in $(A)$ through $(C)$ are mean responses of data unadjusted for institution grouped into deciles by patient sequence number, and dotted curves in $(D)$ are profiles for each institution. A, Procedure time (minutes). B, Total fluoroscopy time (minutes). C, Contrast volume $(\mathrm{mL})$. D, Number of postdilatations.

\section{DISCUSSION}

\section{Principal Findings}

Following the introduction of TA-TAVR across PARTNER-I institutions, procedure time, fluoroscopy time, and volume of contrast medium sharply decreased as patient sequence number increased, indicating a short technical performance learning curve from the perspective of number of cases; however, because of a TF-first policy, it took more than a year on average to traverse this learning curve. This trend appeared to be accounted for largely by patient characteristics associated with prolonged procedures. In conjunction, device success increased while intraprocedural complications and postprocedure AR all decreased within the first 30 to 45 cases; again, however, performing 45 cases extended over a 2 -year period. The composite endpoint of intraprocedural adverse events, death, stroke, and major bleeding within 30 days initially fell, then slightly rose, perhaps due to changing patient profile and unmeasured variables. Importantly, extended procedure times typically encountered at the beginning of an institution's experience, and associated with a greater likelihood of adverse events, were found in multivariable 


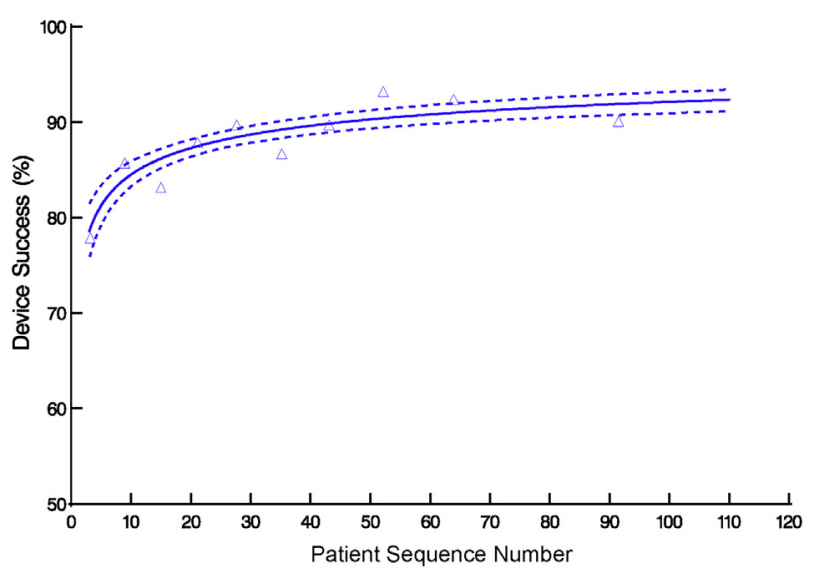

FIGURE 3. Profile of percentage of patients who experienced successful device deployment during transapical transcatheter aortic valve replacement, ordered by institution-specific patient sequence number. Format is as in Figure 2.

analysis not to be an independent risk factor for these adverse events. These findings and those of others ${ }^{10}$ have important implications for forthcoming novel structural heart devices deployed via the left ventricular apex.

\section{Findings in Context}

The concept of a learning curve associated with TATAVR is not new. Aguirre and colleagues ${ }^{11}$ from Cleveland Clinic recently reported on their early experience with TA-TAVR in 150 patients from 2007 to 2013 . They divided patients into 2 groups roughly corresponding to early and mature phases, and found that the need for rescue maneuvers decreased with experience. Although 30-day mortality, bleeding from the left ventricular apex, and deployment of more than 1 valve were similar, 1-year survival improved during the more recent era, perhaps reflecting better patient selection. The authors concluded that despite an elderly, high-risk population, increasing experience was associated with decreasing mortality and complications after TA-TAVR, and that TA-TAVR is as safe and effective as TF-TAVR when performed by skilled teams.

Our finding that occurrence of intraprocedural adverse events and 30-day mortality, stroke, and major bleeding initially fell, then slightly rose may have reflected an increased willingness to enroll more complex patients, and evidence supporting this was found in our multivariable analysis. D'Ancona and colleagues ${ }^{12}$ detailed their similar experience with 500 consecutive high-risk patients undergoing TA-TAVR between 2008 and 2011. They discovered a significant relationship among procedure time, fluoroscopy time, and institutional experience, concluding that a structured training program was necessary to minimize operating room and radiation times, and approximately 100 cases were necessary to traverse the learning curve. They posited that TA-TAVR may be a more difficult procedure than TF-TAVR, but that risk of neurologic
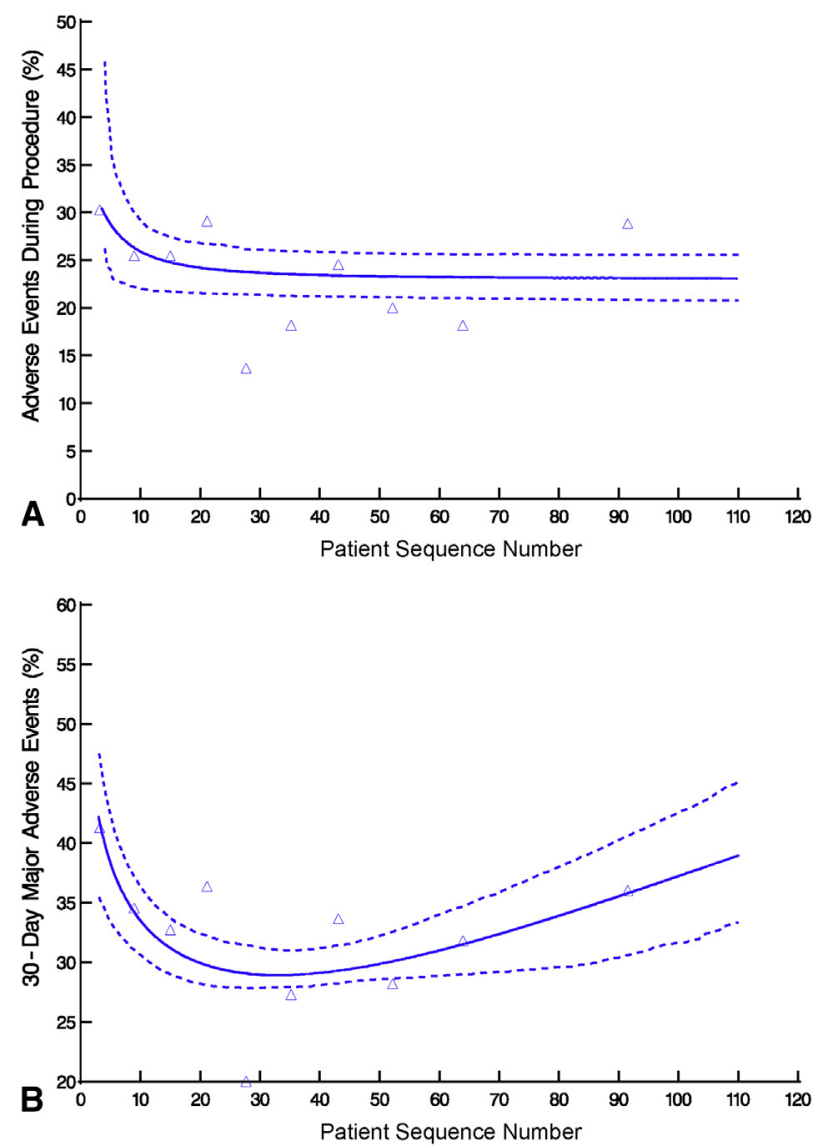

FIGURE 4. Patients who experienced an adverse event during or after transapical transcatheter aortic valve replacement, ordered by institutionspecific patient sequence number. Format is as in Figure 2. A, Adverse events during procedure. B, Major adverse events within 30 days.

complications should be lower due to avoidance of atheromatous debris in the aorta.

In their experience with 299 patients who underwent TATAVR between 2006 and 2010, Kempfert and colleagues ${ }^{13}$ found a low occurrence of stroke and a clear trend toward declining 30-day mortality with increasing experience. They further proposed the existence of a technical learning curve associated with shorter fluoroscopy time, lower contrast dye load, fewer postballoon dilations, and shorter cardiopulmonary bypass time, which translated into shorter procedure times during the second half of their experience. The authors suggested that increased technical facility with wire handling and adjuncts, such as multiple imaging snapshots during stepwise implantation, increased the technical precision of deployment, thereby improving early outcomes.

An important task in assessing learning curves is distinguishing between individual and global experience. In our study of 24 institutions participating in the PARTNER-I trial, we found that institution trial entry date was not significantly associated with adverse outcomes. Importantly, the SAPIEN device itself evolved over time and certain technical efficiencies are likely associated with more 


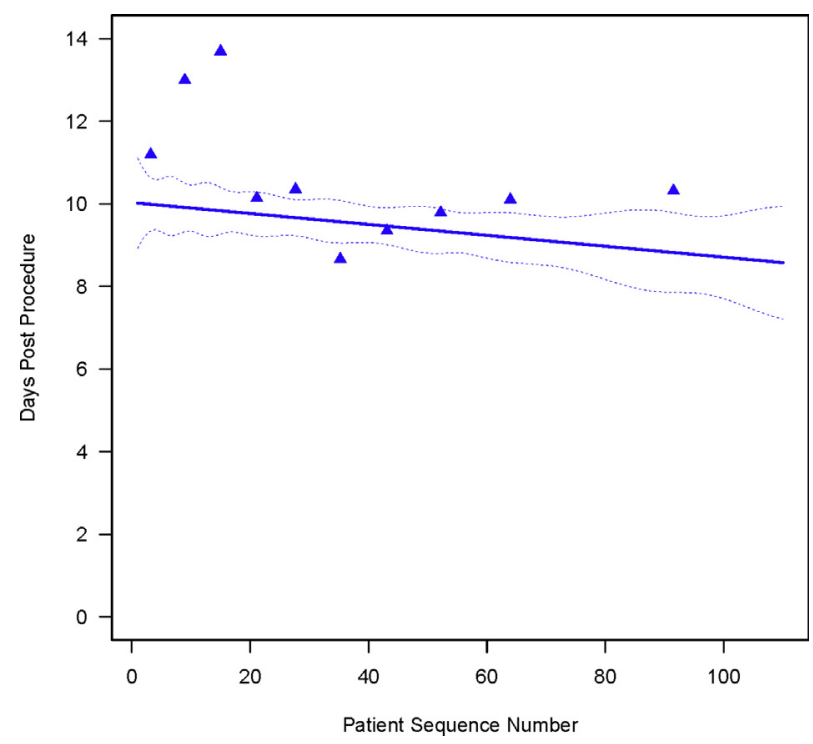

FIGURE 5. Length of hospital stay after transapical transcatheter aortic valve replacement, ordered by institution-specific patient sequence number. Format is as in Figure 2.

sophisticated iterations of both the valve and implantation systems. Enhanced imaging also may be associated with valve deployment accuracy and improved early outcomes.

\section{Clinical Implications}

What does this large TA-TAVR experience from the PARTNER-I trial tell us? First, the learning curve for TATAVR is relatively short in terms of number of cases; these data demonstrate that approximately 30 to 45 cases were required to attain technical proficiency for TA-TAVR. This may relate to the heart teams' previous experience with minimally invasive procedures. Avoiding intraprocedural difficulties and complications that increase procedure time may improve early postoperative outcomes. It is unclear whether evolution of the TA-TAVR platform played more of a role than operator proficiency in improving outcomes.

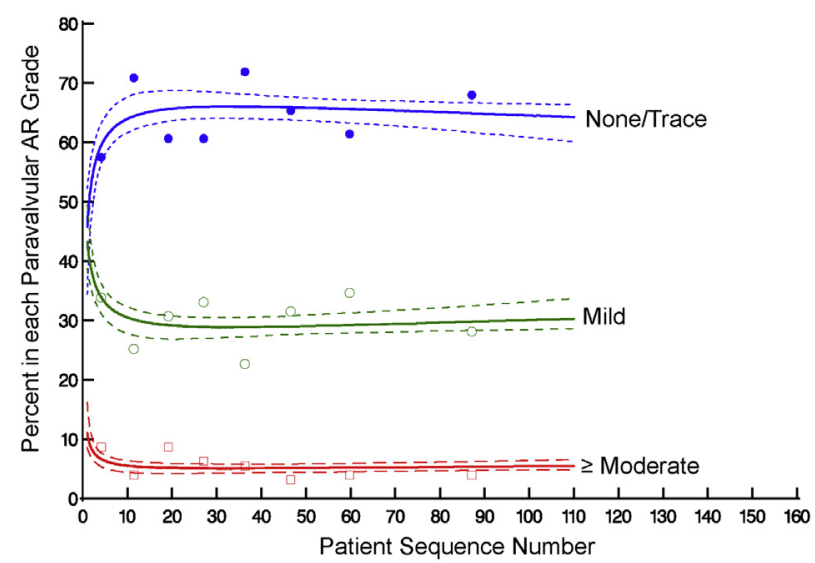

FIGURE 6. Percentage of patients in each paravalvular aortic regurgitation $(A R)$ grade at discharge, ordered by institution-specific patient sequence number. Format is as in Figure 2.

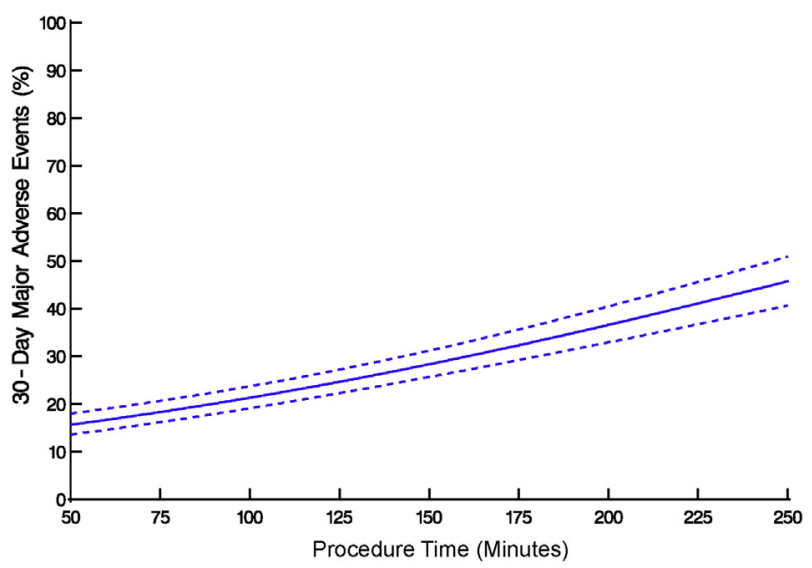

FIGURE 7. Association between procedure time and major adverse events within 30 days after transapical transcatheter aortic valve replacement. Solid line represents average profiles adjusted for institution, enclosed within a dashed $68 \%$ confidence band equivalent to 1 standard error.

It is uncertain how these TA-TAVR advances relate to contemporaneous, but admittedly different, technical advances in TF-TAVR. TF-TAVR is rapidly becoming the procedure of choice in patients undergoing transcatheter aortic valve therapy, particularly as device and sheath sizes decrease. Svensson and colleagues ${ }^{14}$ recently reported the causes of death in PARTNER-I cohorts A and B. They found that TF-TAVR was associated with an increased risk of cardiovascular death, whereas in high-risk patients, both TA-TAVR and AVR had higher early noncardiovascular risk. They concluded that TF-TAVR is preferred for inoperable patients at high risk of noncardiovascular mortality. Unlike TF-TAVR, however, ${ }^{15,16}$ we found little evidence of a technical performance learning curve, and no suggestion that a technical learning curve is associated with adverse outcomes or prolonged postprocedure hospitalization after adjusting for patient factors.

TA-TAVR may benefit certain patients, including those with severe peripheral vascular disease, although other access routes, including transaortic, ${ }^{17,18}$ are currently being evaluated in ongoing clinical trials. Although, subsequent to PARTNER-I, fewer patients are undergoing TAVR via non-TF access, understanding TA-TAVR learning curves and their effect on outcomes is important as the field moves toward structural devices delivered via the left ventricular apex, such as mitral valve replacement.

\section{Limitations}

This is a large study of patients who underwent TA-TAVR with operator teams at 24 institutions. Thus, we were unable to account for variations in team members and whether individual operator experience was more important than a team's accrued experience. Intraoperative risk factors for prolonged procedure time were not recorded and we cannot account for intangible selection factors that may have been at play during the trial. ${ }^{19,20}$ Specific techniques developed and used by 


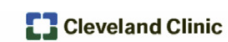

\section{Transapical Transcatheter Aortic Valve Replacement Edwards-Sapien S3 Valve}

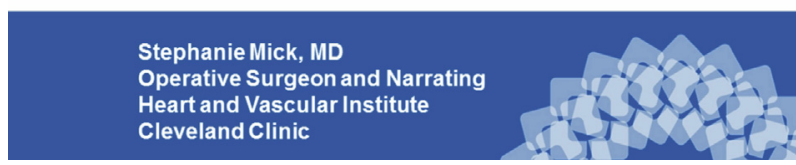

VIDEO 1. Transapical transcatheter aortic valve replacement procedure using an Edwards SAPIEN S3 valve. Video available at http://www. jtcvsonline.org/article/S0022-5223(16)30099-X/addons.

successful teams could not be ascertained from registry data. Finally, this analysis cannot account for differences in learning that existed before the PARTNER-I trial and does not account for learning from larger TF-TAVR experiences that may affect the contemporary learning curve.

\section{CONCLUSIONS}

The learning curve for TA-TAVR was short in terms of number of cases, but long in calendar time due to a TFfirst trial preference. Importantly, technical competence was achieved without compromising patient safety. Although fewer patients are undergoing TAVR via non-TF access, understanding TA-TAVR learning curves and their effect on outcomes is important for structural heart teams as they adopt, learn, and master next-generation therapies delivered via the left ventricular apex.

\section{Conflict of Interest Statement}

R.M.S. is a member of the Clinical Steering Committee at Abbott and S.J.M., consults with Sorin and Abbott, has a patent application with Sorin, and does research with Sorin, Edwards Lifesciences, Abbott, and St Jude; A.D.P. is a proctor for Edwards Lifesciences; M.M. is a member of the executive committee for Edward Lifesciences' PARTNER trial; L.G.S. is on executive committees for Edwards Lifesciences' PARTNER and COMMENCE trials; V.H.T. consults with Edwards Lifesciences; R.M. has research support from Edwards Lifesciences and St Jude Medical, consults with Abbott Vascular, Cordis, and Medtronic, and has equity in Entourage Medical; E.H.B. is on executive committees for Edwards Lifesciences' PARTNER and COMMENCE trials and leads the Cleveland Clinic PARTNER Publications Office, which carries out and publishes independent analyses of PARTNER data. All other authors have nothing to disclose with regard to commercial support.

The authors thank Linda DiPaola at Cleveland Clinic and Steven $\mathrm{Xu}$ at Columbia University for statistical programming; Gina Ventre at Cleveland Clinic and Maria Alu at Columbia University for editing, formatting, and preparing this manuscript for submission; and William Niles Anderson and Hung-Ir Li at Edwards Lifesciences for data validation.

\section{References}

1. Gurvitch R, Tay EL, Wijesinghe N, Ye J, Nietlispach F, Wood DA, et al. Transcatheter aortic valve implantation: lessons from the learning curve of the first 270 high-risk patients. Catheter Cardiovasc Interv. 2011;78:977-84.

2. Alli OO, Booker JD, Lennon RJ, Greason KL, Rihal CS, Holmes DR Jr. Transcatheter aortic valve implantation: assessing the learning curve. JACC Cardiovasc Interv. 2012;5:72-9.

3. Lefevre T, Kappetein AP, Wolner E, Nataf P, Thomas M, Schachinger V, et al. One year follow-up of the multi-centre European PARTNER transcatheter heart valve study. Eur Heart J. 2011;32:148-57.

4. Smith CR, Leon MB, Mack MJ, Miller DC, Moses JW, Svensson LG, et al. Transcatheter versus surgical aortic-valve replacement in high-risk patients. $N$ Engl J Med. 2011;364:2187-98.

5. Walther T, Simon P, Dewey T, Wimmer-Greinecker G, Falk V, Kasimir MT, et al. Transapical minimally invasive aortic valve implantation: multicenter experience. Circulation. 2007;116:I240-5.

6. Leon MB, Piazza N, Nikolsky E, Blackstone EH, Cutlip DE, Kappetein AP, et al. Standardized endpoint definitions for transcatheter aortic valve implantation clinical trials: a consensus report from the Valve Academic Research Consortium. J Am Coll Cardiol. 2011;57:253-69.

7. The PARTNER Trial: Placement of AoRTic TraNscathetER Valves, Version 2.0. Irvine, CA: Edwards Lifesciences; 2008.

8. Cleveland WS, Devlin SJ. Locally weighted regression: an approach to regression analysis by local fitting. J Am Stat Assoc. 1988;83:596-610.

9. Rubin DB. Multiple Imputation for Non-response in Surveys. New York: Wiley; 1987.

10. von Segesser LK, Gerosa G, Borger MA, Ferrari E. Prevention and management of potential adverse events during transapical aortic valve replacement. J Heart Valve Dis. 2013;22:276-86.

11. Aguirre J, Waskowski R, Poddar K, Kapadia S, Krishnaswamy A, McCullough R, et al. Transcatheter aortic valve replacement: experience with the transapical approach, alternate access sites, and concomitant cardiac repairs. J Thorac Cardiovasc Surg. 2014;148:1417-22.

12. D'Ancona G, Pasic M, Unbehaun A, Dreysse S, Drews T, Buz S, et al. Transapical aortic valve implantation: learning curve with reduced operating time and radiation exposure. Ann Thorac Surg. 2014;97:43-7.

13. Kempfert J, Rastan A, Holzhey D, Linke A, Schuler G, van Linden A, et al. Transapical aortic valve implantation: analysis of risk factors and learning experience in 299 patients. Circulation. 2011;124:S124-9.

14. Svensson LG, Blackstone EH, Rajeswaran J, Brozzi N, Leon MB, Smith CR, et al. Comprehensive analysis of mortality among patients undergoing TAVR: results of the PARTNER trial. J Am Coll Cardiol. 2014;64:158-68.

15. Alli O, Rihal CS, Suri RM, Greason KL, Waksman R, Minha S, et al. Learning curves for transfemoral transcatheter aortic valve replacement in the PARTNER-I trial: technical performance. Catheter Cardiovasc Interv. August 10, 2015. [Epub ahead of print].

16. Minha S, Waksman R, Satler LP, Torguson R, Alli O, Rihal CS, et al. Learning curves for transfemoral transcatheter aortic valve replacement in the PARTNER-I Trial: Success and safety. Circ Cardiovasc Interv. October 1, 2015 [Epub ahead of print].

17. Al Kindi AH, Salhab KF, Roselli EE, Kapadia S, Tuzcu EM, Svensson LG. Alternative access options for transcatheter aortic valve replacement in patients with no conventional access and chest pathology. J Thorac Cardiovasc Surg. 2014;147:644-51.

18. Okuyama K, Jilaihawi H, Mirocha J, Nakamura M, Ramzy D, Makkar R, et al. Alternative access for balloon-expandable transcatheter aortic valve replacement: comparison of the transaortic approach using right anterior thoracotomy to partial J-sternotomy. J Thorac Cardiovasc Surg. 2015;149:789-97.

19. Tice JA, Sellke FW, Schaff HV. Transcatheter aortic valve replacement in patients with severe aortic stenosis who are at high risk for surgical complications: summary assessment of the California Technology Assessment Forum. J Thorac Cardiovasc Surg. 2014;148:482-91.e6.

20. Sepehri A, Beggs T, Hassan A, Rigatto C, Shaw-Daigle C, Tangri N, et al. The impact of frailty on outcomes after cardiac surgery: a systematic review. J Thorac Cardiovasc Surg. 2014;148:3110-7.

Key Words: transapical transcatheter aortic valve replacement, learning curve, technical performance, success, safety 
APPENDIX E1. COMPOSITE VARIABLE: MAJOR ADVERSE EVENTS WITHIN 30 DAYS*

\section{Adverse Events During Procedure}

See Table E3.

\section{Bleeding}

Any episode of major internal or external bleeding that causes death, hospitalization, return to the operating room, or permanent injury, or requires transfusion of more than 3 units of packed red blood cells within 24 hours, pericardiocentesis, or an open or endovascular procedure for repair or hemostasis.

\section{Mortality}

Deaths were evaluated to determine if the death was related to the valve or procedure, and subcategorized as cardiovascular, noncardiovascular, or uncategorizable.

\section{Stroke}

Focal neurologic deficit lasting 24 hours or longer, or focal neurologic deficit lasting less than 24 hours with imaging findings of acute infarction or hemorrhage. Stroke was further classified as ischemic, hemorrhagic (epidural, subdural, subarachnoid), or ischemic with hemorrhagic conversion. Both major and minor strokes were considered in this analysis.

\section{Vascular Complications}

Thoracic aortic dissection; access-site or access-related vascular injury (dissection, stenosis, perforation, rupture, arteriovenous fistula, pseudoaneurysm, hematoma, irreversible nerve injury, or compartment syndrome) leading to death, significant blood transfusions (more than 3 units), unplanned percutaneous or surgical intervention, or irreversible end-organ damage (eg, hypogastric artery occlusion causing visceral ischemia or spinal artery injury causing neurologic impairment); distal embolization (noncerebral) from a vascular source resulting in surgery, amputation, or irreversible end-organ damage; or ventricular perforation.

*PARTNER endpoint definitions were originally published in the Supplementary Appendix to Smith CR, Leon MB, Mack MJ, Miller DC, Moses JW, Svensson LG, et al. Transcatheter versus surgical aortic-valve replacement in high-risk patients. N Engl J Med. 2011;364:2187-98.

\section{APPENDIX E2. LEARNING CURVE ANALYSES Overall Learning Curve Profiles}

The continuous variable. We explored shapes of the learning curve for procedure time using a semiparametric mixed-effects model. ${ }^{\mathrm{E} 1}$ To identify and depict the relationship between patient sequence number (sequentially ordered by date of procedure within each institution) and procedure time among institutions, we modeled patient sequence number as a nonparametric function using flexible penalized spline smoothing in a semiparametric mixedeffects model in which the institution effect was treated as a random effect. This semiparametric mixed-effects model was implemented using the SemiPar package in R (http:// www.R-project.org). ${ }^{\mathrm{E} 2, \mathrm{E} 3}$

The mixed-model representation of penalized spline smoothers allows for automatic fitting. Smoothing parameter selection was accomplished via restricted maximum likelihood, and the class of penalized spline smoothers was obtained by estimated best linear unbiased prediction. ${ }^{\mathrm{E} 3}$

Binary (yes/no) variables. We used a fully parametric logistic nonlinear mixed-effects model to explore the shape of the learning curve for binary outcomes with respect to patient sequence number. Institution was treated as a random effect. The model was implemented using PROC NLMIXED in SAS statistical software (SAS v9.2; SAS, Inc, Cary, NC). ${ }^{\mathrm{E}, \mathrm{E} 5}$ The overall trend of the prevalence of the binary response was estimated by averaging the institution-specific trends across patient sequence number. Ordinal variables. We used a nonlinear cumulative logit mixed-effects model to explore the shape of the learning curve $^{\mathrm{E} 5}$ for probability of each aortic regurgitation (AR) grade with respect to patient sequence number. Institution was treated as a random effect. The model was implemented using PROC NLMIXED in SAS statistical software (SAS v9.2; SAS, Inc). ${ }^{\mathrm{E} 4, \mathrm{E} 5}$ Because few patients experienced $3+$ (moderately severe) AR, these patients were combined with $2+$ (moderate) patients for purposes of modeling.

Statistical significance of effects. In all 3 approaches described in the preceding text, our aim was to estimate the trend with respect to patient sequence number, but not the $P$ value for the effect. To produce $P$ values, we performed a focused analysis using each outcome as the response. The only variable considered in the model was a suitable, but simple, transformation of patient sequence number. For continuous variables, we used a linear mixed-effects model (PROC MIXED) to adjust for the institution-specific effect, with institution as a random effect. For binary and ordinal variables, we used a generalized linear mixed-effects model (PROC NLMIXED), with institution as a random effect.

A model adjusting for patient characteristics (fully adjusted model) used variables selected from those in Appendix E3. Due to the limited capability for variable selection in PROC NLMIXED and PROC MIXED, we used PROC LOGISTIC, PROC REG, and bootstrap bagging 
for preliminary variable screening, as described in subsequent text under "Multivariable Analysis."

Estimates based on fully parametric and semiparametric regression trend models. Estimates based on trend models have been included for specific patient sequence numbers. These include numerical estimates for the 1st, 5th, 15th, and every 15th procedure thereafter. Estimates go up to 90 patients. These estimates encompass approximately $95 \%$ of patients in each group.

\section{Effect of Trial Entry Date on Learning Curve}

We investigated the relationship between institutionspecific trial entry date and the learning curve by data exploration methods. We used conditional and stratification plots to summarize trends for continuous variables. Temporal trends stratified by trial entry date are summarized across patient sequence number using a locally weighted scatterplot smoothing (loess) curve.

\section{Learning Curve for Procedure Time}

A detailed study of asymptotic procedure time and number of cases needed to attain the asymptote used an inverse polynomial mixed-effects model. To begin the analysis, we modeled the relation of procedure time to patient sequence number. We explored 4 models: an exponential Type III mixed-effects model, a first-degree hyperbolic mixedeffects model, a hyperbolic mixed-effects model using the square root of sequence number, and a hyperbolic mixedeffects model using an estimated power of sequence number.

Results of these approaches were concordant. However, allowing the data to determine the power for the hyperbolic model provided the closest fit of the parametric model to the data. We therefore have illustrated the findings for this model.

Consider the inverse polynomial (specifically hyperbola) to model procedure time:

$$
\frac{1}{Y}=\frac{1}{A}+\frac{B}{X^{C}}
$$

where $A$ is the horizontal asymptote; $B$ is the shaping parameter such that when $B<0$, it is a decreasing function, and when $B>0$, it is an increasing function; $Y$ is procedure time; $X$ is sequence number; and $C$ transforms the scale of $X$. Note that for $C>0$, as sequence number $X$ gets larger, the second term approaches 0 , and thus $1 / Y=1 / A$, and $Y=A$. That is, $A$ is procedure time when the learning curve has become flat (asymptotic).

The smaller the absolute value of $B$, the faster the rate at which the institution-specific learning curve reaches asymptotic procedure time, as depicted in the following figure:
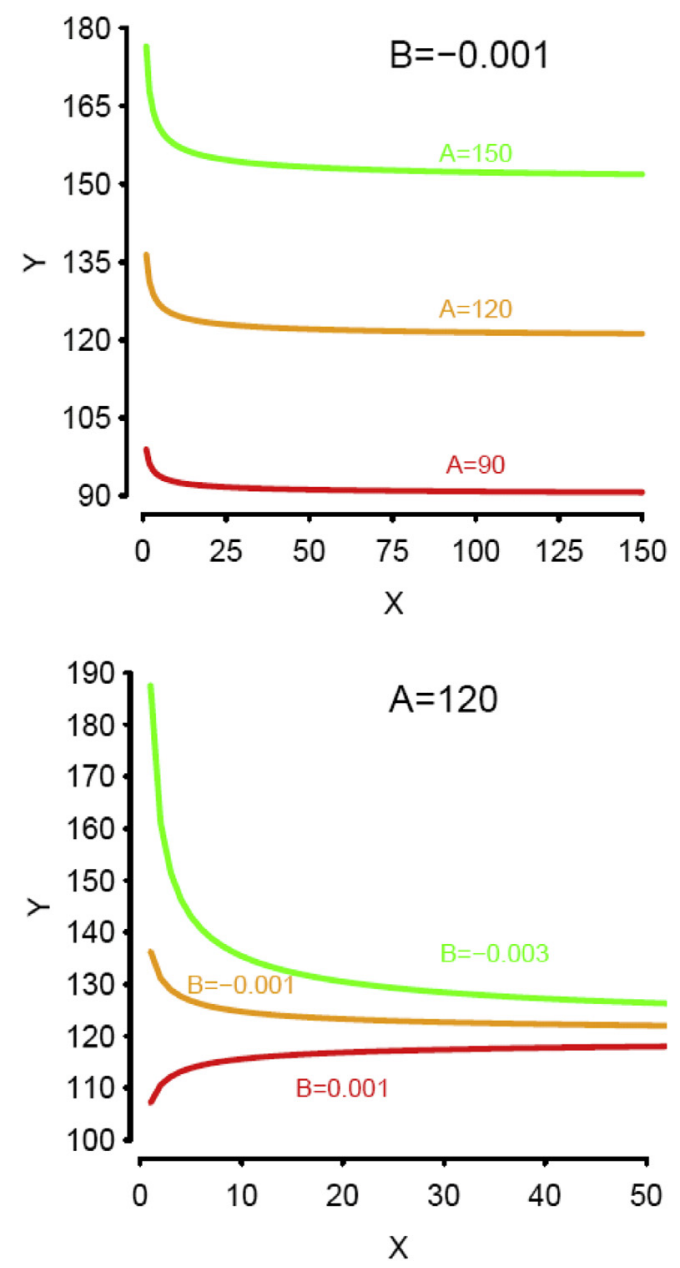

\section{Mixed-Effects Model}

We used this nonlinear equation and defined the following nonlinear mixed-effects model, with institution number as the clustering unit:

$$
Y_{i}=\frac{A_{i} X_{i}^{C}}{X_{i}^{C}+A_{i} B_{i}}+\epsilon_{i}, i=1, \ldots, 26,
$$

where $A_{i}=a_{0}+a_{i}$ is the institution-specific horizontal asymptote of procedure time, $B_{i}=b_{0}+b_{i}$ is the institution-specific shape, with random effects $\left[a_{i}, b_{i}\right]^{T}=\beta_{i} \sim N_{2}(0, \boldsymbol{G})$, and $\in_{i} \mid \beta_{i} \sim N_{n i}\left(0, \sigma^{2} I\right)$. The conditional model can be written as:

$$
\frac{1}{E\left(Y_{i} \mid \beta_{i}\right)}=\frac{1}{A_{i}}+\frac{B_{i}}{X_{i}^{C^{\prime}}}
$$

In the case of procedure time, $\boldsymbol{Y}_{i}, A_{i}$ is the procedure time at which the $i^{\text {th }}$ institution-specific learning curve reaches an asymptote (becomes flat), and $C$ is a scale-stretching exponent on procedure time to account for more protracted learning curves than a strict hyperbolic function. The smaller the absolute value of $B_{i}$ the higher the rate at 
which the institution-specific learning curve reaches asymptotic procedure time. We implemented and estimated the institution-specific asymptotic procedure times, institution-specific shapes, and profiles using PROC NLMIXED. To then estimate the institution-specific patient number at which the institution-specific curve asymptotes, we must set a convergence criterion, which should be related to having near zero difference in predicted procedure time as sequence number increases. We arbitrarily set the convergence to a difference of 15 seconds between consecutive procedure times.

\section{Multivariable Analysis}

We extended the mixed-effects model to perform multivariable analyses to identify the patient and procedure variables associated with procedure time.

We constructed a multivariable model using procedure time as the response. The nonlinear mixed-effect model was augmented as follows:

$$
\begin{aligned}
& A=A_{O}+A_{I} \text { Trial entry date }+a_{i} \text { and } \\
& B=B_{O}+B_{I} \text { Trial entry date }+b_{i} \\
& \text { and }
\end{aligned}
$$

$$
Y_{i}=\frac{A_{i} X_{i}^{C}}{X_{i}^{C}+A_{i} B_{i}}+Z_{i} \beta+\epsilon_{i}, i=1, \ldots, 26
$$

where $\boldsymbol{Z}$ is a vector of covariables.

For better mathematical tractability, procedure time was scaled as "(procedure time/120)."

SAS PROC NLMIXED has limited capability to explore multivariable relations; thus, we initially screened variables in Appendix E3 using ordinary multivariable linear regression (PROC REG in SAS) with an assumption of independence of observations, entry criteria of $P=.10$, and stay criteria of $P=.05$.

We used bootstrap bagging (bootstrap aggregation) ${ }^{\mathrm{E} 6, \mathrm{E} 7}$ for variable selection. This was a 4 -step process. First, a patient was randomly selected from the original dataset to begin a new dataset. The original dataset continued to be sampled until the new dataset was $100 \%$ the size of the original. Second, risk factors were identified using automated forward stepwise selection. Third, results of variable selection were stored. These 3 steps were repeated 1000 times. Finally, the frequency of occurrence of variables in these 1000 models was ascertained, and this indicated the reliability of each variable (aggregation step). All variables, or 1 variable within a cluster, with bootstrap reliability of $50 \%$ or greater were retained in the final analysis.

This analysis was performed simply to identify possible candidates for our model. These candidates and their transformations, if any, were entered into our mixed model and eliminated one-by-one until all variables remaining had $P \leq .05$.

\section{Association of Technical Performance With Clinical Outcomes}

We assessed the association of the following technical performance variables with 30-day major adverse events and postprocedure length of stay: total procedure time (minutes), fluoroscopy time (minutes), contrast volume used during procedure (milliliters), pacing count during balloon aortic valvotomy, pacing count during valve deployment, number of postdeployment dilatations, frequency of percutaneous closure device usage, and $23-\mathrm{mm}$ or $26-\mathrm{mm}$ valve. Multivariable analysis of 30-day major adverse events. We used a logistic mixed-effects model with institution as the random effect to explore the association of technical performance with the probability of a 30-day major adverse event. The model was implemented using PROC NLMIXED in SAS.

We used bootstrap variable selection to identify patient and procedure variables (see Appendix E3) associated with a 30-day major adverse event. We then incorporated continuous and binary technical performance variables into the multivariable model, along with the selected patient and procedure variables. Due to the limited capability for variable selection in PROC NLMIXED, we used PROC LOGISTIC and performed variable screening as described in the preceding text.

Multivariable analysis of postprocedure length of stay. We used a linear mixed-effects model with institution as the random effect to explore the association of technical performance variables with postprocedure length of stay. The parametric mixed-effects model was implemented using PROC MIXED in SAS. The natural logarithmic transformation (LN [length of stay]) was used to normalize the data. Due to the limited capability for variable selection in PROC MIXED, we used PROC REG and performed variable screening as described in the preceding text.

\section{Missing Value Imputation}

A number of variables examined in multivariable analyses had missing values. We used fivefold multiple imputation $^{\mathrm{E} 8}$ using a Markov Chain Monte Carlo technique to impute missing values (SAS PROC MI). In multivariable modeling, for each imputed complete dataset, we estimated the regression coefficients and their variance-covariance matrix. Then, following Rubin, ${ }^{\mathrm{E} 8}$ we combined estimates from the 5 models (SAS PROC MIANALYZE) to yield final regression coefficient estimates, the variance-covariance matrix, and $P$ values.

\section{APPENDIX E3. VARIABLES USED IN ANALYSES Baseline Patient Characteristics}

Demographics. Age (years), sex, race or ethnicity (white), height $(\mathrm{cm})$, weight $(\mathrm{kg})$, weight-height ratio, body mass index $\left(\mathrm{kg} / \mathrm{m}^{2}\right)$, body surface area $\left(\mathrm{m}^{2}\right)$. 
Functional health status. Syncope not related to atrioventricular block, exertional syncope, New York Heart Association functional class, Society of Thoracic Surgeons (STS) predicted operative mortality, STS $>10$, frailty.

Aortic valve pathophysiology (including echocardiographic studies). Previous balloon aortic valvotomy, native valve calcified, calcified anulus, native valve leaflet fusion, aortic valve $(\mathrm{AV})$ peak velocity $(\mathrm{cm} / \mathrm{s}), \mathrm{AV}$ timevelocity integral $(\mathrm{cm}), \mathrm{AV}$ area (effective orifice area) $\left(\mathrm{cm}^{2}\right)$, AV mean gradient $(\mathrm{mm} \mathrm{Hg})$, AV peak gradient $(\mathrm{mm} \mathrm{Hg}), \mathrm{AV}$ regurgitation severity.

Aortic vasculopathy. Pathology: calcified aorta.

Cerebrovascular disease. Cerebrovascular disease, including carotid disease, carotid disease, previous carotid endarterectomy or carotid stent, previous stroke.

Coronary artery disease. Coronary artery disease, angina, coronary artery stenosis (none $>50 \%$, any $>50 \%$, left main trunk [LMT] $>50 \%$, left anterior descending [LAD] $>50 \%$, left circumflex [LCX] $>50 \%$, right coronary artery $[\mathrm{RCA}]>50 \%$, left internal thoracic artery $>50 \%$, preprocedure stenosis in a saphenous vein graft $>50 \%$, coronary artery stenosis: other $>50 \%$, grafts $>50 \%$ ), prior percutaneous coronary intervention, prior number of coronary artery bypass graftings $(0,1,2)$, number of systems diseased $\geq 50 \%$ (0-system disease $\geq 50 \%$, 1 -system disease $\geq 50 \%$, 0 - or 1 -system disease $\geq 50 \%$, 2-system disease $\geq 50 \%$, 3-system disease $\geq 50 \%$, 2 - or 3 -system disease $\geq 50 \%$ ), LMT disease $>0 \%$, LAD disease $>0 \%$, LCX disease $>0 \%$, RCA disease $>0 \%$.

Ventricular function. Myocardial infarction.

Other cardiac comorbidity. Mitral valve (MV) disease, baseline MV regurgitation severity, tricuspid valve disease, arrhythmia, atrial fibrillation, pacemaker implant, cardiomyopathy, previous cardiovascular intervention, other previous cardiovascular interventions or surgery.

Left ventricular outflow tract, including proximal aorta. Aortic root diameter $(\mathrm{cm})$.

Preprocedure echocardiogram: left ventricular morphology and function. Left ventricular (LV) enddiastolic dimension $(\mathrm{cm})$, LV end-systolic dimension $(\mathrm{cm})$, visual ejection fraction $(\%), \mathrm{LV}$ diastolic posterior wall thickness $(\mathrm{cm}), \mathrm{LV}$ systolic posterior wall thickness $(\mathrm{cm})$, interventricular septal diastolic dimension $(\mathrm{cm})$, interventricular septal systolic dimension (cm), LV mass (g), LV mass index $\left(\mathrm{g} / \mathrm{m}^{2}\right)$, cardiac output $(\mathrm{L} / \mathrm{min})$, cardiac index $\left(\mathrm{L} \cdot \mathrm{min}^{-1} \cdot \mathrm{m}^{-2}\right)$, heart rate (beats per minute), calculated stroke volume from Doppler at baseline $(\mathrm{mL})$, stroke volume index $\left(\mathrm{mL} / \mathrm{m}^{2}\right)$.

Pre-balloon aortic valvotomy catheterization hemodynamics. Systolic pulmonary artery (PA) pressure (mm Hg), diastolic PA pressure $(\mathrm{mm} \mathrm{Hg})$, mean PA pressure $(\mathrm{mm} \mathrm{Hg})$, systolic aortic pressure $(\mathrm{mm} \mathrm{Hg})$, diastolic aortic pressure $(\mathrm{mm} \mathrm{Hg})$, mean aortic pressure $(\mathrm{mm} \mathrm{Hg})$, mean right atrial pressure $(\mathrm{mm} \mathrm{Hg})$.

Noncardiac comorbidity. Diabetes mellitus (yes/no, type 2, baseline drug treatment: insulin), smoking, pulmonary disease, oxygen-dependent pulmonary disease, history of chronic pulmonary disease, history of oxygen-dependent chronic pulmonary disease, hyperlipidemia, renal disease, gastrointestinal condition, cancer, bilirubin $(\mathrm{mg} / \mathrm{dL})$, creatinine $(\mathrm{mg} / \mathrm{dL})$, creatinine clearance (Cockcroft-Gault, $\mathrm{mL} / \mathrm{min})$, glomerular filtration rate $\left(\mathrm{mL} \cdot \mathrm{min}^{-1} \cdot 1.73 \mathrm{~m}^{-2}\right)$, blood urea nitrogen $(\mathrm{mg} / \mathrm{dL})$, hemoglobin $(\mathrm{g} / \mathrm{dL})$, hematocrit $(\%)$, international normalized ratio, platelet count $(\mathrm{k} / \mu \mathrm{L})$, white blood cell count $(\mathrm{k} / \mu \mathrm{L})$, albumin $(\mathrm{g} / \mathrm{dL})$.

Baseline drug treatment. Angiotensin-converting enzyme inhibitor, antiarrhythmic, anticoagulant, antiplatelet, beta blocker, calcium channel blocker, diuretic, nitrate, statin.

\section{Procedure Characteristics*}

Procedure time (min), fluoroscopy time ( $\mathrm{min})$, contrast volume $(\mathrm{mL})$, number of post dilatations, number of rapid cardiac pacing attempts during balloon aortic valvotomy, number of rapid cardiac pacing attempts during valve deployment.

Prosthetic valve. Small valve $(23 \mathrm{~mm})$ implanted.

\section{Experience}

Patient sequence number by institution, intensity: interval between procedures by institution, trial entry date by institution, institution.

*Variables considered when assessing the influence of technical performance on outcomes.

\section{E-References}

E1. Ruppert D, Wand MP, Carroll RJ. Semiparametric Regression. Cambridge, UK Cambridge University Press; 2003.

E2. R Core Team. R: A language and environment for statistical computing. Available at: http://www.R-project.org. Accessed 2014.

E3. Wand M. Semiparametric regression. Available at: http://cran.r-project.org/web/ packages/SemiPar/SemiPar.pdf .1.0-3. 2013. Accessed 2014.

E4. Diggle PJ, Heagerty PJ, Liang KY, Zeger SL. Analysis of Longitudinal Data. New York: Oxford University Press; 2002.

E5. Rajeswaran J, Blackstone EH. A multiphase non-linear mixed effects model: An application to spirometry after lung transplantation. Stat Methods Med Res. June 11, 2014 [Epub ahead of print].

E6. Breiman L. Bagging predictors. Machine Learning. 1996;24:123-40.

E7. Sauerbrei W, Schumacher M. A bootstrap resampling procedure for model building: application to the Cox regression model. Stat Med. 1992;11: 2093-109.

E8. Rubin DB. Multiple Imputation for Non-response in Surveys. New York: Wiley; 1987. 


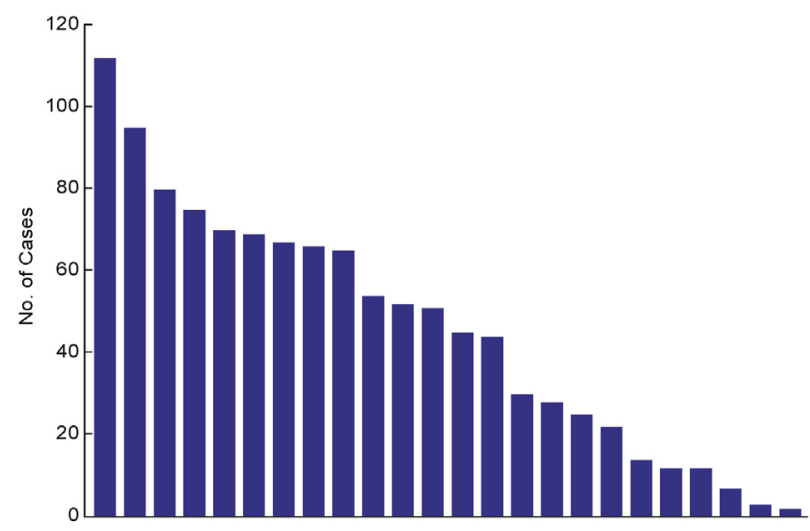

Institution

FIGURE E1. Number of transapical transcatheter aortic valve replacements performed per institution.

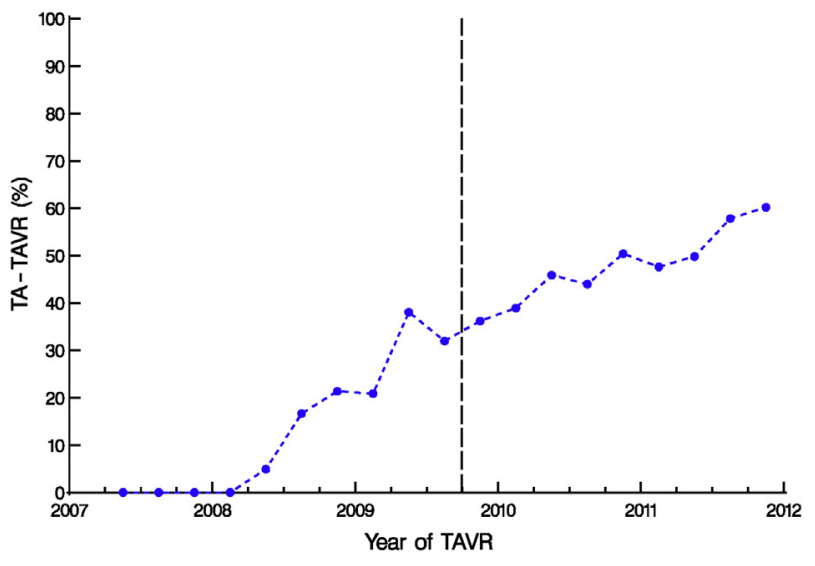

FIGURE E2. Percentage of transapical procedures over the course of the PARTNER-I trial. Each dot represents the percentage of transapical procedures for each yearly quarter. The randomized trial ended in September 2009, illustrated by vertical dashed line. TA-TAVR, Transapical transcatheter aortic valve replacement. 

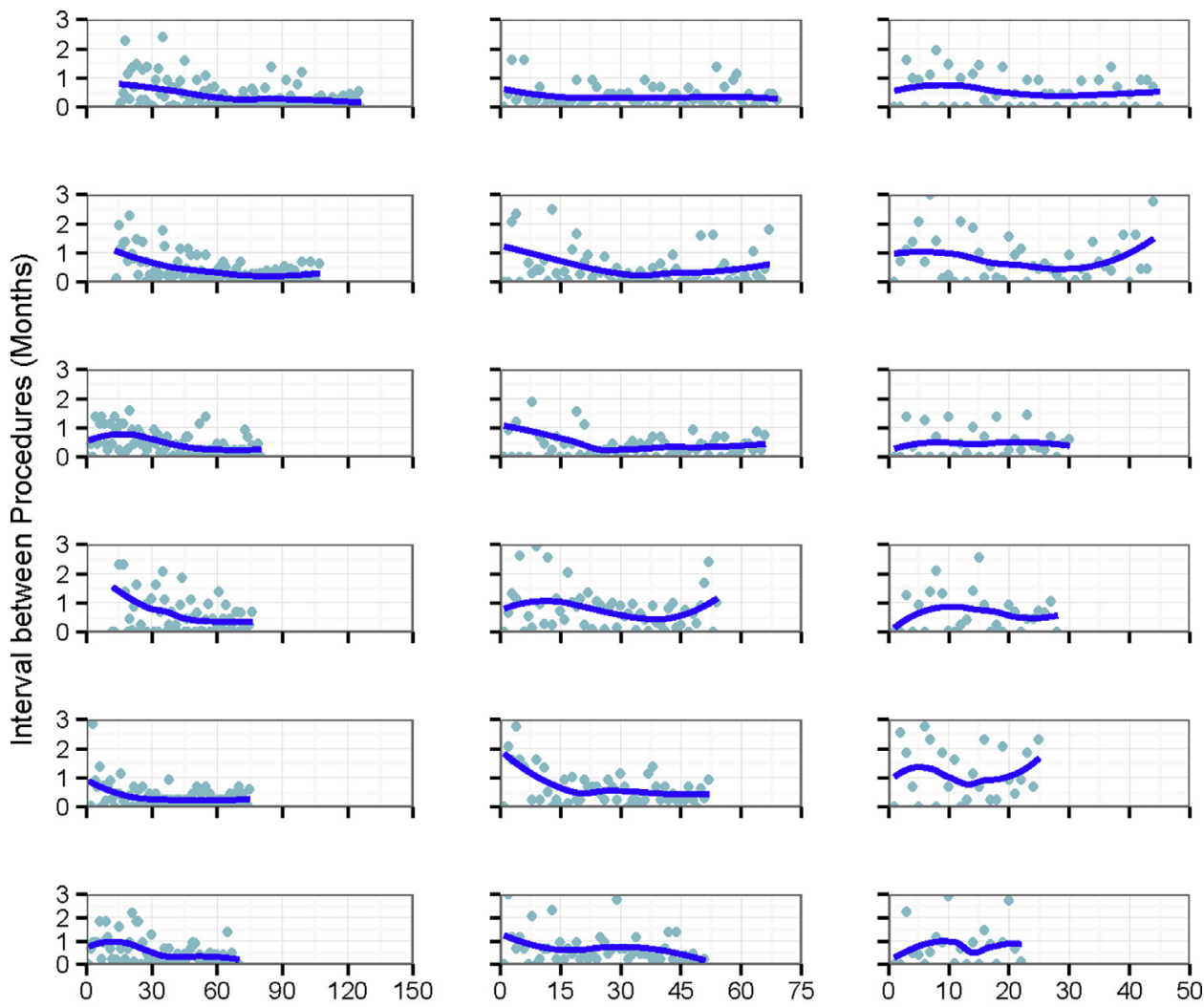

Patient Sequence Number

FIGURE E3. Interval between sequential transapical transcatheter aortic valve replacements at each of the 18 institutions that performed at least 22 procedures. Each dot is an interval; solid line is a loess estimate of trend. Notice that values tended to be elevated early in the institutions' experience. Interval between procedures is inversely proportional to institution volume (the lower the volume, the longer the interval). 

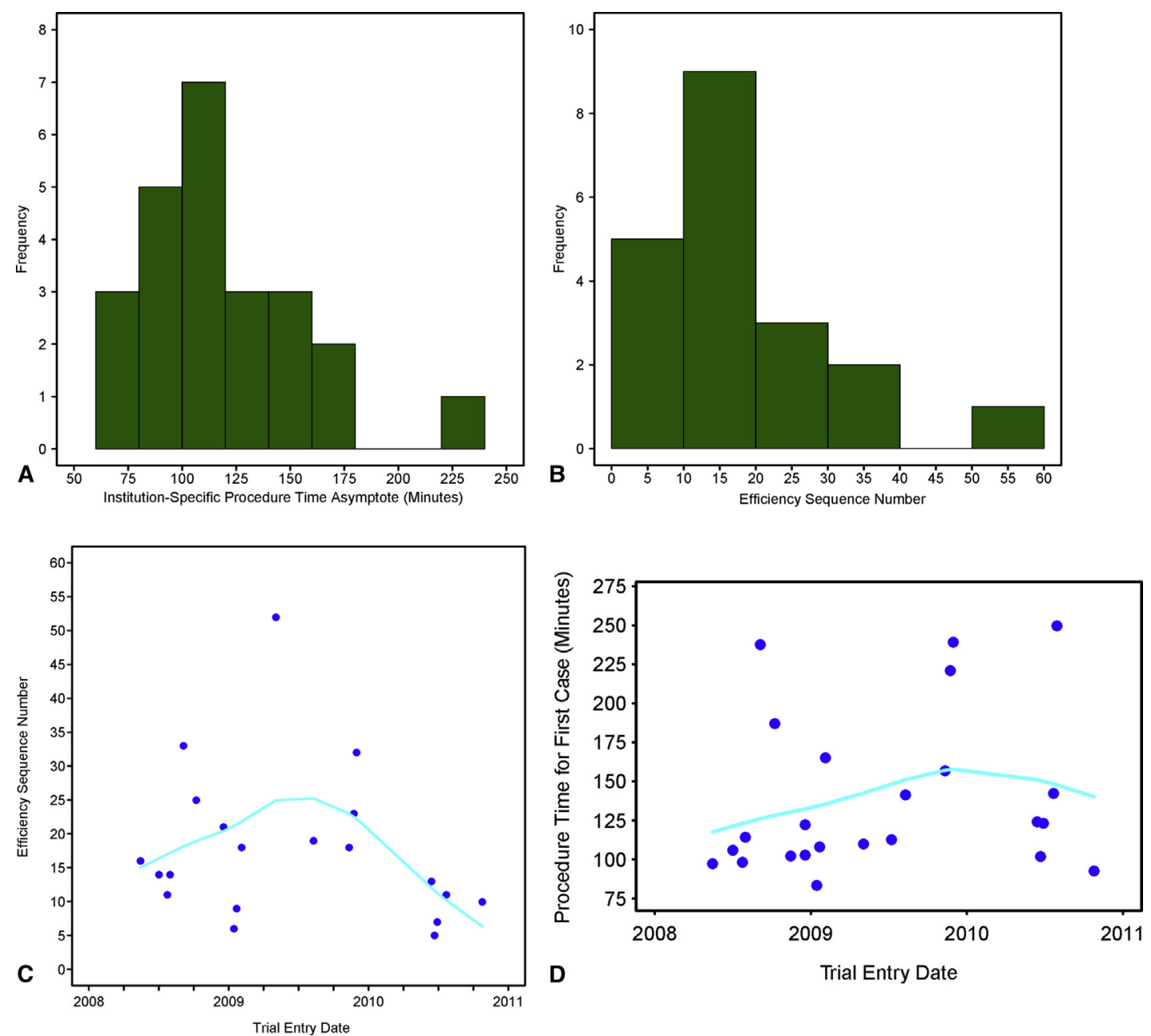

FIGURE E4. Model parameter estimates of non-risk-adjusted institution-specific learning curves for procedure time. "Asymptote" refers to the minimum procedure time when the learning curve is over; "efficiency sequence number" refers to when this asymptote has been reached. A, Frequency distribution of institution-specific asymptotes, expressed in minutes. B. Frequency distributions of institution-specific sequence numbers at which asymptotes were reached. C, Relationship of sequence number at which asymptote was reached to institution trial entry date. D, Model-based procedure time by institution trial entry date. 

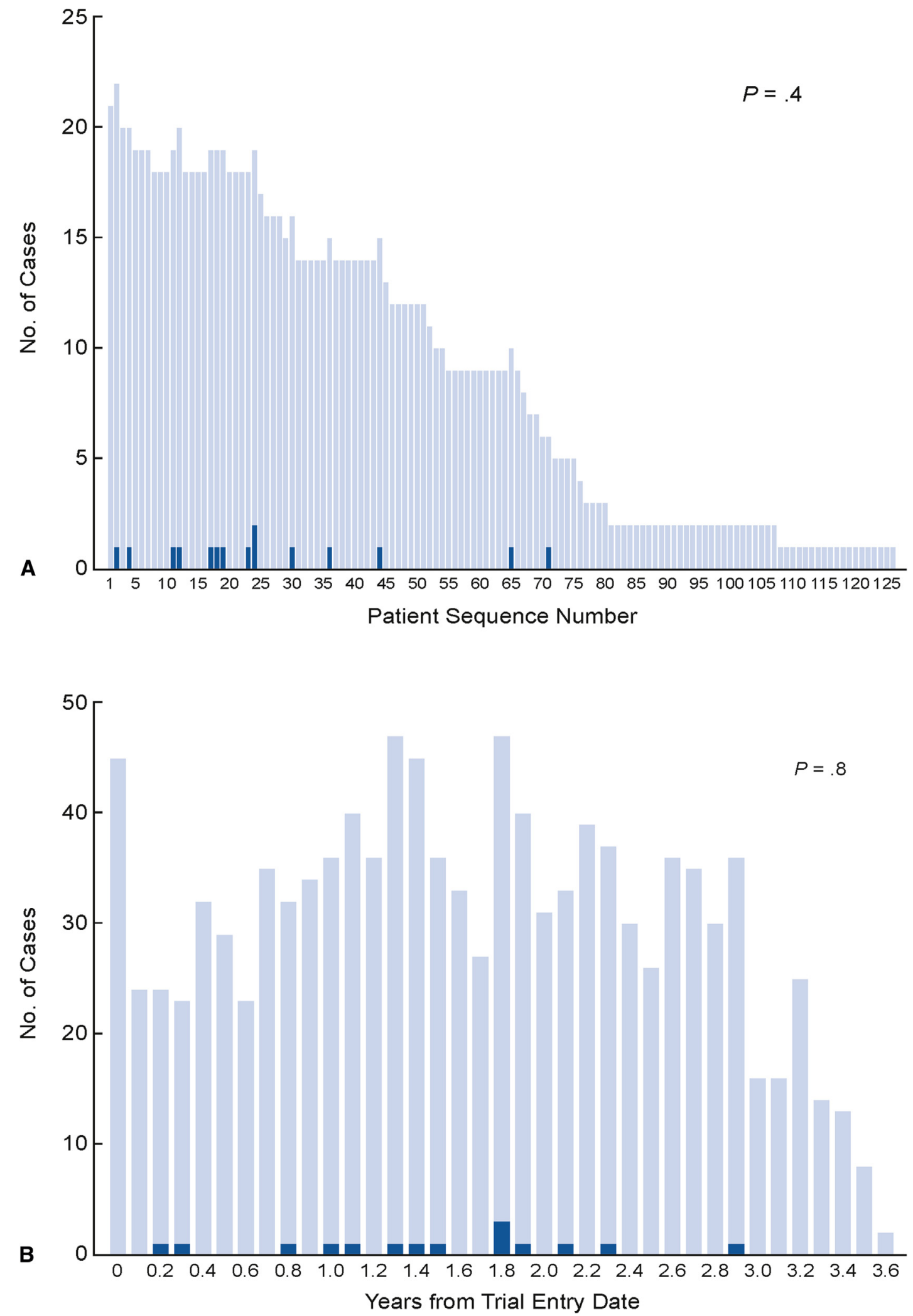

FIGURE E5. Occurrence of 4 ventricular injuries and 11 myocardial perforations during the study period. Light blue bars represent number of cases performed, and dark blue areas are cases in which intraprocedural myocardial perforation or ventricular injury occurred. A, Events as a function of institutionspecific patient sequence number. B, Events as a function of institution-specific years from trial entry date. 

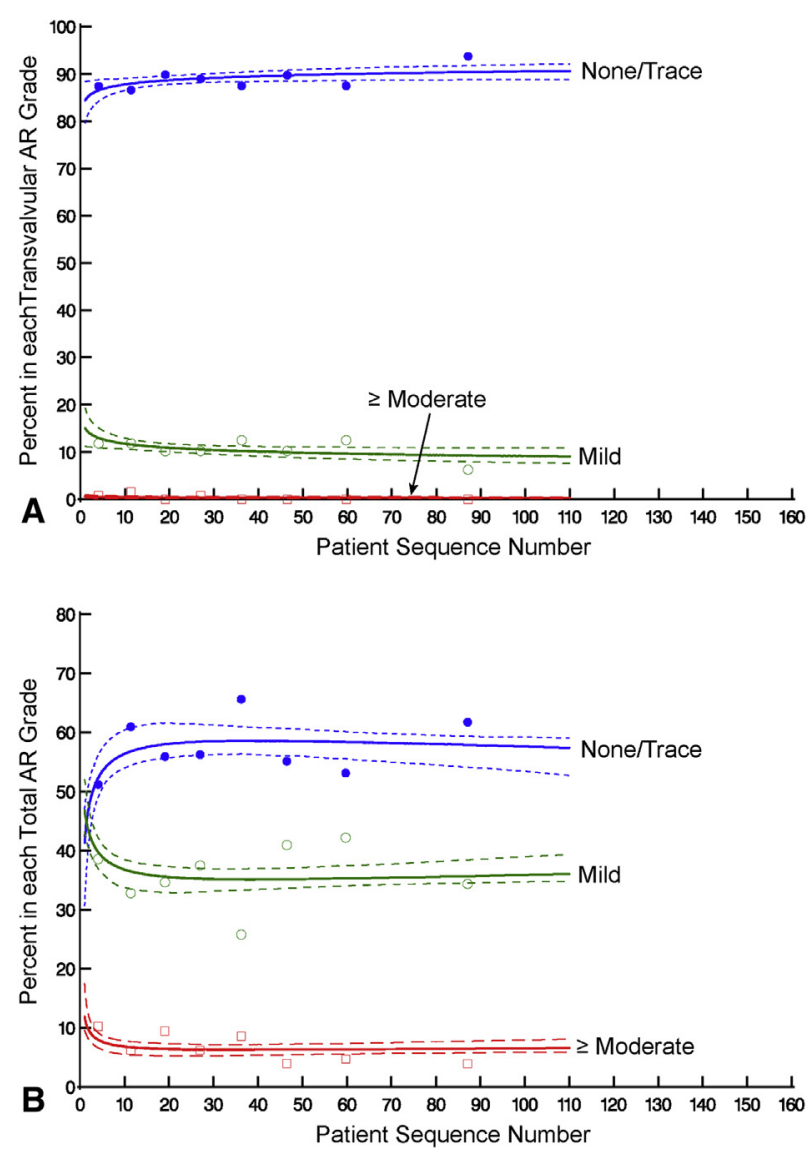

FIGURE E6. Percentage of patients in each aortic regurgitation $(A R)$ grade at discharge, ordered by institution-specific patient sequence number. Format is as in Figure 1. A, AR. B, Total AR. 

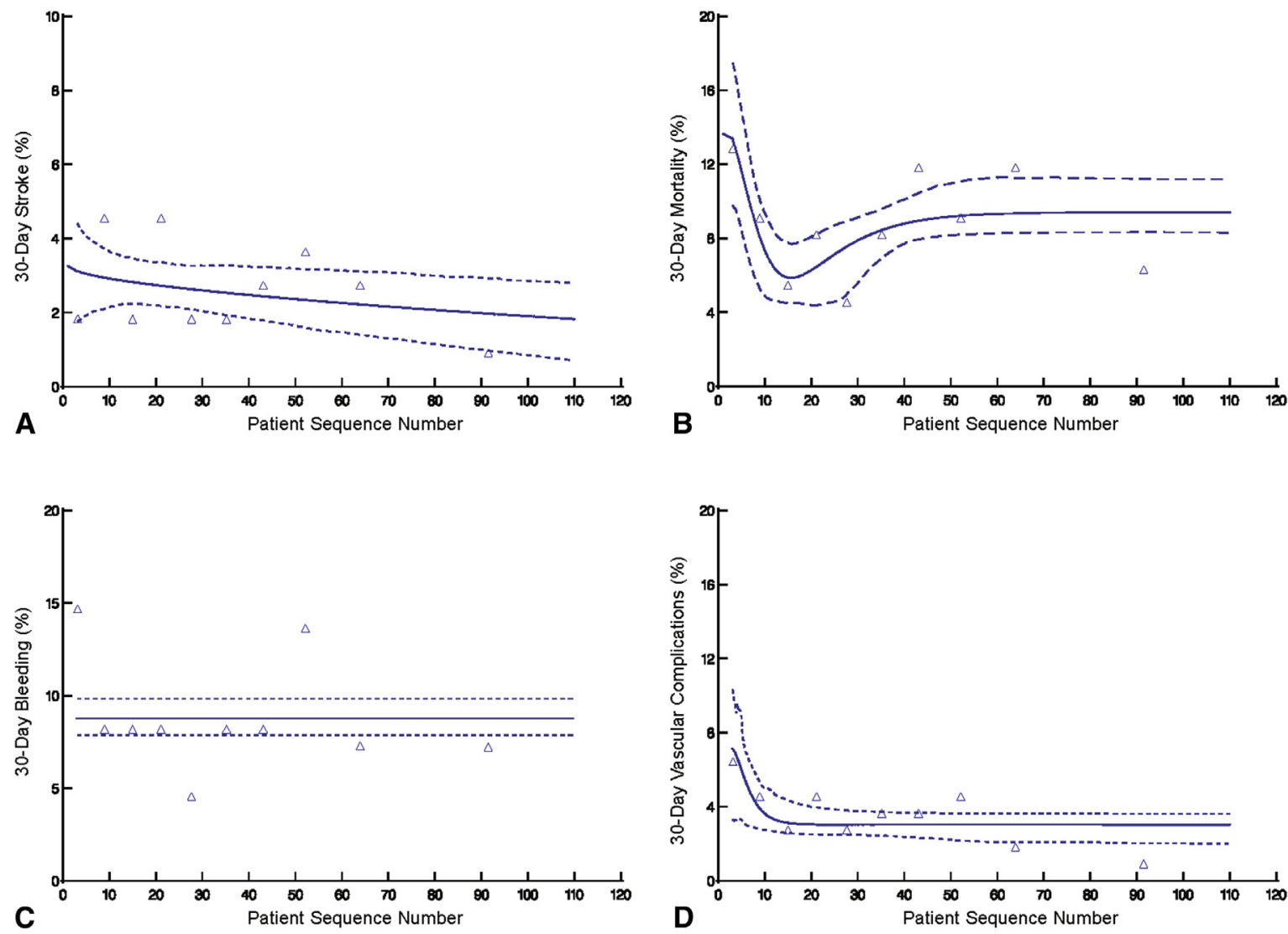

FIGURE E7. Thirty-day major adverse events after transapical transcatheter aortic valve replacement, ordered by institution-specific patient sequence number. Format is as in Figure 1. A, Stroke. B, Mortality. C, Bleeding. D, Vascular complications. 
TABLE E1. Baseline patient characteristics

\begin{tabular}{|c|c|c|}
\hline Characteristic & $\mathbf{n}^{*}$ & n $(\%)$ or mean \pm SD \\
\hline \multicolumn{3}{|l|}{ Demographics } \\
\hline Female & 1100 & $574(52)$ \\
\hline Age, y & 1100 & $85 \pm 6.4$ \\
\hline \multicolumn{3}{|l|}{ Race } \\
\hline Black & 1100 & $12(1.1)$ \\
\hline White & 1100 & $1049(95)$ \\
\hline Weight, kg & 1099 & $71 \pm 18$ \\
\hline Height, $\mathrm{cm}$ & 1096 & $164 \pm 11$ \\
\hline \multicolumn{3}{|l|}{ Aortic valve pathology } \\
\hline AV peak velocity, $\mathrm{cm} / \mathrm{s}$ & 1066 & $414 \pm 63$ \\
\hline $\mathrm{AV}$ area, $\mathrm{cm}^{2}$ & 1056 & $0.64 \pm 0.19$ \\
\hline $\mathrm{AV}$ mean gradient, $\mathrm{mm} \mathrm{Hg}$ & 1073 & $44 \pm 14$ \\
\hline \multicolumn{3}{|l|}{ Cardiac comorbidity } \\
\hline Stroke volume, $\mathrm{mL}$ & 1057 & $64 \pm 18$ \\
\hline Heart rate, beats per min & 1081 & $71 \pm 24$ \\
\hline MV disease & 1099 & $852(78)$ \\
\hline Heart failure & 1097 & $1079(98)$ \\
\hline Ejection fraction, $\%$ & 1079 & $52 \pm 13$ \\
\hline Cardiomyopathy & 1099 & $154(14)$ \\
\hline Coronary artery disease & 1099 & $906(82)$ \\
\hline Myocardial infarction & 1097 & $320(29)$ \\
\hline Atrial fibrillation & 1098 & $236(21)$ \\
\hline Porcelain aorta & 1092 & 19 (1.7) \\
\hline \multicolumn{3}{|l|}{ Noncardiac comorbidity } \\
\hline Hypertension & 1100 & $1051(96)$ \\
\hline Diabetes & 1100 & $392(36)$ \\
\hline Chronic pulmonary disease & 1100 & $499(45)$ \\
\hline Hyperlipidemia & 1100 & $956(87)$ \\
\hline Renal disease & 1100 & $193(18)$ \\
\hline Peripheral arterial disease & 1100 & $1073(98)$ \\
\hline Cerebral vascular disease, including carotid disease & 1099 & $473(43)$ \\
\hline Smoking & 1100 & $601(55)$ \\
\hline \multicolumn{3}{|l|}{ Risk profile } \\
\hline STS risk score & 1098 & $12 \pm 4.1$ \\
\hline \multicolumn{3}{|l|}{ Frailty } \\
\hline 6-min walk, m & 743 & $166 \pm 105$ \\
\hline \multicolumn{3}{|l|}{ Previous procedures } \\
\hline Cardiovascular intervention & 1100 & $927(84)$ \\
\hline Percutaneous coronary intervention & 1099 & $502(46)$ \\
\hline Coronary artery bypass grafting & 1100 & $557(51)$ \\
\hline Balloon aortic valvotomy & 1096 & $289(26)$ \\
\hline Carotid endarterectomy/carotid stent & 1098 & $178(16)$ \\
\hline Peripheral arterial intervention & 1098 & $114(10)$ \\
\hline Peripheral bypass graft & 1098 & $55(5)$ \\
\hline Pacemaker & 1099 & $231(21)$ \\
\hline Other previous cardiovascular interventions/surgery & 1100 & $73(6.6)$ \\
\hline \multicolumn{3}{|l|}{ Medications } \\
\hline ACE inhibitor & 1100 & $447(41)$ \\
\hline Anticoagulant & 1100 & $204(19)$ \\
\hline Antiplatelet & 1100 & $336(31)$ \\
\hline Beta blocker & 1100 & $734(67)$ \\
\hline Diuretic & 1100 & $750(68)$ \\
\hline Nitrate & 1100 & $201(18)$ \\
\hline Statin & 1100 & $743(68)$ \\
\hline
\end{tabular}

$S D$, Standard deviation; $A V$, aortic valve; $M V$, mitral valve; $S T S$, Society of Thoracic Surgeons; $A C E$, angiotensin-converting enzyme. *Patients with data available. 
TABLE E2. Study population overall and by transapical transcatheter aortic valve replacement

\begin{tabular}{lcr}
\hline Group & Overall & TA-TAVR \\
\hline Roll-in & 62 & 19 \\
Cohort 1A & 344 & 104 \\
Cohort 1B & 175 & 0 \\
RCA & 40 & 0 \\
NRCA & 2000 & 977 \\
Total & 2621 & 1100 \\
\hline TA-TAVR, Transapical transcatheter aortic valve replacement; $R C A$, randomized \\
continued access; $N R C A$, nonrandomized continued access.
\end{tabular}

TABLE E3. Adverse events during transapical transcatheter aortic valve replacement

\begin{tabular}{lc}
\hline & $\mathbf{n}=\mathbf{3 4 6}$ \\
& $\mathbf{n}(\%)$ \\
\hline Arrhythmia & $47(14)$ \\
Hypotension & $44(13)$ \\
Bleeding & $42(12)$ \\
Vascular hemorrhage & $32(9.2)$ \\
Conduction defect & $31(9)$ \\
Abnormal laboratory value & $23(6.6)$ \\
Perivalvular leak & $20(5.8)$ \\
Aortic regurgitation without paravalvular leak & $11(3.2)$ \\
Perforation or damage to myocardium & $11(3.2)$ \\
Respiratory & $7(2.0)$ \\
Ischemia & $5(1.4)$ \\
Ventricular injury & $4(1.2)$ \\
Device embolization & $3(0.87)$ \\
Transient ischemic attack, stroke, or psychomotor deficit & $3(0.87)$ \\
Infection & $3(0.87)$ \\
Hypertension & $3(0.87)$ \\
Hematoma & $2(0.58)$ \\
Heart failure & $2(0.58)$ \\
Mitral valve injury & $2(0.58)$ \\
Access site nerve injury & $1(0.29)$ \\
Thromboembolism & $1(0.29)$ \\
Mitral regurgitation & $1(0.29)$ \\
Pericardial effusion & $1(0.29)$ \\
Pleural effusion & $1(0.29)$ \\
Myocardial infarction & $1(0.29)$ \\
Systemic peripheral nerve injury & $1(0.29)$ \\
Device migration & $0(0)$ \\
Electrolyte imbalance & $0(0)$ \\
Anular dissection & $0(0)$ \\
Gastrointestinal & $0(0)$ \\
Nonstructural valve dysfunction & $0(0)$ \\
Valvular stenosis & $0(0)$ \\
Other & $44(13)$ \\
\hline
\end{tabular}


TABLE E4. Mean estimates of technical and outcomes endpoints by patient sequence number

\begin{tabular}{|c|c|c|c|c|c|c|c|c|}
\hline \multirow[b]{2}{*}{ Endpoints } & \multicolumn{8}{|c|}{ Patient sequence number } \\
\hline & 1 & 5 & 15 & 30 & 45 & 60 & 75 & 90 \\
\hline \multicolumn{9}{|l|}{ Technical } \\
\hline Procedure time, min & 131 & 127 & 121 & 116 & 117 & 118 & 117 & 117 \\
\hline Fluoroscopy time, min & 14.5 & 14.3 & 13.9 & 13.3 & 12.7 & 12.2 & 11.8 & 11.4 \\
\hline Contrast volume, $\mathrm{mL}$ & 114 & 110 & 102 & 96 & 92 & 90 & 86 & 83 \\
\hline Postdeployment dilatation, $\mathrm{n}$ & 0.089 & 0.095 & 0.108 & 0.122 & 0.134 & 0.146 & 0.149 & 0.134 \\
\hline \multicolumn{9}{|l|}{ Outcomes } \\
\hline Device success, $\%$ & 72 & 81 & 86 & 89 & 90 & 91 & 91 & 92 \\
\hline Adverse events during procedure, $\%$ & 31 & 29 & 25 & 24 & 23 & 23 & 23 & 23 \\
\hline \multicolumn{9}{|c|}{ Aortic regurgitation grade at discharge, $\%$} \\
\hline \multicolumn{9}{|l|}{ Paravalvular } \\
\hline None/trace & 46 & 61 & 65 & 66 & 66 & 66 & 65 & 65 \\
\hline Mild & 43 & 33 & 30 & 29 & 29 & 29 & 30 & 30 \\
\hline Moderate or severe & 11 & 6.3 & 5.3 & 5.1 & 5.1 & 5.2 & 5.3 & 5.3 \\
\hline \multicolumn{9}{|l|}{ Transvalvular } \\
\hline None/trace & 84 & 87 & 88 & 89 & 90 & 90 & 90 & 90 \\
\hline Mild & 15 & 13 & 11 & 10 & 10 & 10 & 9.4 & 9.2 \\
\hline Moderate or severe & 0.58 & 0.48 & 0.42 & 0.38 & 0.36 & 0.35 & 0.34 & 0.33 \\
\hline \multicolumn{9}{|l|}{ Total } \\
\hline None/trace & 41 & 53 & 58 & 58 & 59 & 58 & 58 & 58 \\
\hline Mild & 47 & 39 & 36 & 35 & 35 & 35 & 36 & 36 \\
\hline Moderate or severe & 12 & 7.6 & 6.5 & 6.3 & 6.3 & 6.3 & 6.4 & 6.5 \\
\hline Postprocedure length of stay, $d$ & 10 & 10 & 10 & 10 & 9.4 & 9.2 & 9.0 & 8.8 \\
\hline \multicolumn{9}{|l|}{ Adverse events within $30 \mathrm{~d}, \%$} \\
\hline Stroke & 3.3 & 3.0 & 2.8 & 2.6 & 2.4 & 2.3 & 2.1 & 2.0 \\
\hline Mortality & 14 & 12 & 5.9 & 7.9 & 9.0 & 9.3 & 9.4 & 9.4 \\
\hline Major bleeding & 8.8 & 8.8 & 8.8 & 8.8 & 8.8 & 8.8 & 8.8 & 8.8 \\
\hline Major vascular complication & 5.2 & 6.0 & 3.1 & 3.0 & 3.0 & 3.0 & 3.0 & 3.0 \\
\hline Composite major adverse events & 51 & 38 & 31 & 29 & 29 & 31 & 33 & 36 \\
\hline
\end{tabular}

TABLE E5. Patient and procedure characteristics associated with major adverse events occurring within 30 days after transapical transcatheter aortic valve replacement

\begin{tabular}{|c|c|c|c|}
\hline Characteristic & Coefficient \pm SE & $\boldsymbol{P}$ & Reliability, \%* \\
\hline \multicolumn{4}{|l|}{ Patient } \\
\hline No coronary artery disease & $-0.45 \pm 0.19$ & .02 & 86 \\
\hline Syncope not related to atrioventricular block & $0.44 \pm 0.22$ & .04 & 69 \\
\hline Higher international normalized ratio $\dagger$ & $-1.7 \pm 0.53$ & .002 & 72 \\
\hline Antiplatelet therapy & $0.69 \pm 0.15$ & $<.0001$ & 94 \\
\hline Lower hemoglobin & $-0.14 \pm 0.044$ & .002 & 54 \\
\hline \multicolumn{4}{|l|}{ Trending } \\
\hline Lower patient sequence number $\ddagger$ & $0.017 \pm 0.0099$ & .09 & 62 \\
\hline Trial entry date (years from 01/01/2007) & $0.086 \pm 0.14$ & 6 & 15 \\
\hline Interval between procedures & $0.25 \pm 1.1$ & .8 & 16 \\
\hline \multicolumn{4}{|l|}{ Technical Performance } \\
\hline Longer procedure time & $0.0075 \pm 0.0013$ & $<.0001$ & 100 \\
\hline Longer fluoroscopy time $\S$ & $0.38 \pm 0.18$ & .04 & 63 \\
\hline Larger contrast volume & $0.00013 \pm 0.0011$ & .9 & 22 \\
\hline Fewer postdilatations & $-0.25 \pm 0.20$ & .2 & 14 \\
\hline Fewer rapid cardiac pacings during BAV & $-0.083 \pm 0.11$ & .4 & 11 \\
\hline More rapid cardiac pacings during valve deployment & $0.064 \pm 0.079$ & .4 & 11 \\
\hline $23-\mathrm{mm}$ valve & $0.059 \pm 0.15$ & .7 & 4.9 \\
\hline
\end{tabular}

$S E$, Standard error; $B A V$, balloon aortic valvotomy. *Percentage of times variable appeared in 1000 bootstrap models. †Inverse transformation: (1/International Normalized Ratio) $)^{2}$. Inverse transformation: 1/(patient sequence number/45). §Natural log transformation: LN (fluoroscopy time). 
TABLE E6. Patient and procedure characteristics associated with major adverse events occurring within 30 days, with procedure time the only technical performance variable

\begin{tabular}{|c|c|c|c|}
\hline Characteristic & Coefficient \pm SE & $\boldsymbol{P}$ & Reliability $(\%)^{*}$ \\
\hline \multicolumn{4}{|l|}{ Patient } \\
\hline No coronary artery disease & $-0.46 \pm 0.18$ & .01 & 86 \\
\hline Syncope not related to atrioventricular block & $0.46 \pm 0.21$ & .03 & 69 \\
\hline Higher international normalized ratio $\dagger$ & $-1.5 \pm 0.51$ & .003 & 72 \\
\hline Antiplatelet therapy & $0.66 \pm 0.15$ & $<.0001$ & 94 \\
\hline Lower hemoglobin & $-0.14 \pm 0.044$ & .001 & 54 \\
\hline \multicolumn{4}{|l|}{ Learning curve } \\
\hline Lower patient sequence number $\ddagger$ & $0.019 \pm 0.010$ & .06 & 62 \\
\hline Trial entry date (years from 01/01/2007) & $0.086 \pm 0.14$ & .5 & 15 \\
\hline Interval between procedures & $0.61 \pm 1.1$ & 6 & 16 \\
\hline \multicolumn{4}{|l|}{ Technical performance } \\
\hline Predicted learning curve effect on procedure time & $-0.0014 \pm 0.0068$ & .8 & $-\S$ \\
\hline Predicted covariate effect on procedure time & $0.014 \pm 0.0073$ & .05 & $-\S$ \\
\hline $\begin{array}{l}\text { Contribution of events during procedure, } \\
\text { unobserved factors, and random variability }\end{array}$ & $0.0093 \pm 0.0014$ & $<.0001$ & $-\S$ \\
\hline
\end{tabular}

